\title{
Flattening the COVID-19 Curve With Natural Killer Cell Based Immunotherapies
}

\author{
Marisa Market ${ }^{1,2 \dagger}$, Leonard Angka ${ }^{1,2 \dagger}$, Andre B. Martel ${ }^{1,2,3}$, Donald Bastin ${ }^{4}$, \\ Oladunni Olanubi ${ }^{1,2}$, Gayashan Tennakoon ${ }^{1}$, Dominique M. Boucher ${ }^{2}$, Juliana Ng ${ }^{1}$, \\ Michele Ardolino ${ }^{1,2,5 * t}$ and Rebecca C. Auer ${ }^{1,2,3 *+}$ \\ ${ }^{1}$ Cancer Therapeutics Program, Ottawa Hospital Research Institute, Ottawa, ON, Canada, ${ }^{2}$ Department of Biochemistry, \\ Microbiology, and Immunology, University of Ottawa, Ottawa, ON, Canada, ${ }^{3}$ Division of General Surgery, Department of \\ Surgery, University of Ottawa, Ottawa, ON, Canada, ${ }^{4}$ Schulich School of Medicine, University of Western Ontario, London, \\ ON, Canada, ${ }^{5}$ Centre for Infection, Immunity, and Inflammation, University of Ottawa, Ottawa, ON, Canada
}

\section{OPEN ACCESS}

Edited by:

Thierry Walzer,

UMR5308 Centre International de Recherche en Infectiologie

(CIRI), France

Reviewed by:

Stephen Noel Waggoner,

Cincinnati Children's Hospital Medical

Center, United States

Jacques Zimmer,

Luxembourg Institute of

Health, Luxembourg

*Correspondence:

Michele Ardolino

m.ardolino@uottawa.ca

Rebecca C. Auer

raver@toh.ca

tThese authors have contributed equally to this work

Specialty section:

This article was submitted to NK and Innate Lymphoid Cell Biology,

a section of the journal

Frontiers in Immunology

Received: 28 April 2020

Accepted: 09 June 2020

Published: 23 June 2020

Citation:

Market M, Angka L, Martel AB, Bastin D, Olanubi O, Tennakoon G, Boucher DM, Ng J, Ardolino M and Auer RC (2020) Flattening the COVID-19 Curve With Natural Killer

Cell Based Immunotherapies.

Front. Immunol. 11:1512.

doi: 10.3389/fimmu.2020.01512
Natural Killer (NK) cells are innate immune responders critical for viral clearance and immunomodulation. Despite their vital role in viral infection, the contribution of NK cells in fighting SARS-CoV-2 has not yet been directly investigated. Insights into pathophysiology and therapeutic opportunities can therefore be inferred from studies assessing NK cell phenotype and function during SARS, MERS, and COVID-19. These studies suggest a reduction in circulating NK cell numbers and/or an exhausted phenotype following infection and hint toward the dampening of NK cell responses by coronaviruses. Reduced circulating NK cell levels and exhaustion may be directly responsible for the progression and severity of COVID-19. Conversely, in light of data linking inflammation with coronavirus disease severity, it is necessary to examine NK cell potential in mediating immunopathology. A common feature of coronavirus infections is that significant morbidity and mortality is associated with lung injury and acute respiratory distress syndrome resulting from an exaggerated immune response, of which NK cells are an important component. In this review, we summarize the current understanding of how NK cells respond in both early and late coronavirus infections, and the implication for ongoing COVID-19 clinical trials. Using this immunological lens, we outline recommendations for therapeutic strategies against COVID-19 in clearing the virus while preventing the harm of immunopathological responses.

Keywords: NK cells, COVID-19, innate immunity, immunotherapy, interferon

\section{INTRODUCTION}

Natural Killer (NK) cells are a key component of the innate immune system and are critical in the response to many viral infections in humans and animal models (1-3). In addition to their beneficial antiviral role, NK cells have also been associated with immunopathology in infections such as respiratory syncytial virus (RSV) (4), influenza A virus (5-8), and hepatitis B (9). Additionally, in the context of non-respiratory viral infections by HIV and HCV, NK cells appear to act as a rheostat by eliminating activated $\mathrm{CD} 4+$ and $\mathrm{CD} 8+\mathrm{T}$ cells, thus preventing $\mathrm{T}$ cell-mediated autoimmunity (10). The etiologic agent of the 2019 outbreak of pneumonia in Wuhan, China, was identified as belonging to the Coronaviridae family and named Severe Acute Respiratory Syndrome 
coronavirus 2 (SARS-CoV-2). This virus causes the coronavirus Disease 2019 (COVID-19) which was declared a pandemic by the World Health Organization (WHO) on March 11th, 2020 $(11,12)$. With the paucity of information currently available, there is a lack of consensus on the role played by NK cells in the response to coronavirus $(\mathrm{CoV})$ infection. In this review, we will explore evidence for both the protective and pathological role that NK cells may play in CoV infection. Based on this knowledge we will comment on immune modulating treatment options that are being developed for the current COVID-19 crisis.

\section{Coronaviruses and Recent Outbreaks}

First discovered in the 1960s, CoVs are part of the Coronaviridae family of enveloped positive single-strand RNA viruses $(13,14)$. The subfamily Orthocoronaviridae includes four genera: alphacoronavirus, betacoronavirus, gammacoronavirus, and deltacoronavirus (15). Alpha- and betacoronaviruses circulate in mammals, including bats, gammacoronaviruses infect mostly avian species, and deltacoronaviruses infect birds and mammals (15). Low pathogenic human CoVs (hCoVs), such as HCoV299E (16), infect upper airways and etiological studies suggest they account for $15-30 \%$ of common colds $(17,18)$. On the other hand, highly pathogenic CoVs infect the lower respiratory tract and can cause severe pneumonia (19). These highly pathogenic CoVs include SARS-CoV-1, the virus responsible for the 2002-2004 Severe Acute Respiratory Syndrome (SARS) epidemic, and MERS-CoV, the virus responsible for the outbreak of Middle Eastern Respiratory Syndrome (MERS) in 2015 (19-21). While highly pathogenic CoVs have become a relatively recent issue for humans; feline, canine, and bovine CoVs have long been recognized as significant pathogens with implications in veterinary medicine and agriculture $(22,23)$. All CoVs have a roughly $30 \mathrm{~kb}$ genome packed into an enveloped helical capsid ranging from 80 to $120 \mathrm{~nm}$ (24). At minimum, Coronaviridae members encode 4 structural and 16 non-structural proteins (14) with the family owing its name to the crown-like appearance produced by their spike (S) proteins (25). Mutations in the $S$ protein have allowed SARS-CoV1/2 to co-opt ACE2 or MERS$\mathrm{CoV}$ to co-opt dipeptidyl peptidase 4 (DPP4) receptor/CD26 as viral entry receptors, thus facilitating the zoonosis of nonhuman CoVs $(15,26-28)$. In addition, another mechanism that may have allowed these viruses to adapt to human hosts is through $\mathrm{S}$ protein cleavage by host cell proteases to expose the S2 domain fusion peptide, which induces viral and cellular membrane fusion and results in the release of viral genome into the cytoplasm (15). Genetic sequencing revealed SARS-CoV-2 to be a betacoronavirus that shares $79.0 \%$ nucleotide identity with SARS-CoV-1 and 51.8\% identity to MERS-CoV (29).

The epidemic of SARS in 2002-2004 caused by SARS-CoV1 illustrated the devastating potential of coronaviruses to cause serious disease in humans (24). SARS ultimately reached 29 countries and 5 continents causing over 8,000 infections and over 900 deaths. The basic reproductive rate $\left(\mathrm{R}_{0}\right)$ or the number of expected cases arising from one infected individual, ranges from 2 to $4(20,30,31)$. With its reservoir in bats, SARS-CoV1 is a zoonosis that was transmitted to humans by palm civets $(24,32,33)$. SARS-CoV-1 infects lung pneumocytes (34) and enterocytes in the digestive tract (35) most often producing flulike symptoms $(36,37)$. More severe presentations including pneumonia, pronounced lymphopenia, liver abnormalities, and acute respiratory distress syndrome (ARDS) were also reported, with most fatalities due to respiratory failure (19, 36-39).

The subsequent MERS-CoV outbreak in 2015 also originated in bats, with dromedary camels being the intermediary host (14, $40,41)$. The $\mathrm{R}_{0}$ for MERS-CoV is estimated to be under 1 (21). The extent of MERS-CoV transmission was more limited than SARS-CoV-1, but its case fatality rate was greater with 2,494 cases over 27 countries and 858 deaths being reported at the end of 2019 (21). Common presentations for MERS-CoV include fever, dyspnea, muscle pain, and digestive tract symptoms and disease progression is more likely in those with comorbidities (42).

Like SARS-CoV-1 and MERS-CoV, SARS-CoV-2 is thought to have originated in bats through an unknown intermediary host (43). At the time of writing, the number of global infections is estimated to be over 5,000,000 with over 340,000 deaths (44) and the $\mathrm{R}_{0}$ is roughly 2.2 (45). Like other diseases caused by infectious $\mathrm{CoVs}$, most patients present with flu-like symptoms including fever, cough, and lethargy, with the development of pneumonia and ARDS often proving fatal (46). Furthermore, patients with underlying conditions are at risk for further complications if infected with COVID-19, such as those with cardiovascular disease (47). SARS-CoV-2 has been posthumously detected in not only the lungs, but the pharynx, heart, liver, brain, and kidneys (48). Transmission of SARS-CoV-2 is thought to mainly occur through direct contact/inhalation of respiratory droplets and aerosols from infected carriers, but indirect transmission by fomites has also been reported, although less efficient $(49,50)$. SARS-CoV-2 viral entrance is thought to be mediated by binding of the $S$ protein to the ACE2 receptor $(51,52)$, although this is still under debate (53). While direct cytopathic effects are thought to play a major role in $\mathrm{CoV}$ pathology, studies have suggested that a dysregulated immune response resulting in pathological inflammation is also partly responsible (19). With the current pandemic already surpassing the previous CoV outbreaks (54), rapid deployment of novel approaches to understanding and treating coronavirus infections are needed.

\section{NK CELLS AS INNATE VIRAL KILLERS Sensing RNA Viruses}

Innate immunity is essential in disease prevention and viral clearance. Among the first responders to viral infections, tissueresident macrophages and dendritic cells (DCs) (55) recognize evolutionarily conserved microbial structures termed pathogenassociated molecular patterns (PAMPs) via germline-encoded pattern recognition receptors (PRRs) (56). In the context of respiratory RNA viruses, airway epithelial cells, that also express some PRRs (57), are often infected and have a major role in the first line of defense. TLR3, TLR7, TLR8, MDA-5, and RIGI are PRR expressed by immune and non-immune cells that are especially relevant in fighting respiratory RNA viruses, such as Coronaviruses (57). Sensing through PRRs results in the transcription of genes involved in the inflammatory response, with type I interferons (IFNs) $($ IFN- $\alpha / \beta)$ production being a 
critical part of the antiviral response (58). Type I IFNs are produced by many immune and non-immune cells $(55,57,59)$ and in addition to eliciting intrinsic antiviral responses (60), they are also essential to prime innate and adaptive lymphocytes, including NK cells (61).

\section{NK Cells as Viral Responders}

NK cells are cytotoxic lymphocytes that directly target infected, stressed, or transformed cells and play a critical role in bridging the innate and the adaptive immune responses (62). In humans, mature NK cells comprise $10-15 \%$ of total peripheral blood leukocytes and are described phenotypically as $\mathrm{CD} 3^{-} \mathrm{CD} 14^{-}$ $\mathrm{CD}^{-} 9^{-} \mathrm{CD}^{+} 6^{+} \mathrm{CD}^{+/-}$(63). NK cells do not undergo clonal selection but instead express several germline-encoded receptors that regulate their activity $(62,64,65)$. Upon viral infection, host cells become more susceptible to NK cell killing through: (i) upregulation of self-encoded molecules induced by infection/cellular stress $(66,67)$ that bind activating NK cell receptors such as Natural Cytotoxicity Receptors (NCRs) (NKp30, NKp44, and NKp46) (68), C-type lectin-like receptors NKG2D and NKp80 (69), and co-activating receptors such as DNAM-1 (70); (ii) downregulation of ligands for inhibitory receptors such as Killer Immunoglobulin-like Receptors (KIRs) (71-73) and the C-type lectin-like receptor CD94-NKG2A $(74,75)$ which suppress NK cell activation, and; (iii) direct recognition of viral moieties, via engagement of PAMPS (76) or transmembrane activating receptors such as mouse Ly $49 \mathrm{H}$ (77) or human NKG2C (78). Moreover, NK cells can eliminate virus-infected cells via CD16-mediated antibody-dependent cellmediated cytotoxicity (ADCC), which has been shown to be particularly important for herpesvirus clearance (79). Finally, NK cell activity is modulated by cytokines, including, but not limited to, the activating cytokines interleukin (IL)-2/12/15/18 (80) and type I IFN, which can be produced by virally infected cells or activated antigen presenting cells $(81,82)$. IL-2/12/15/18, alone or in combination, promotes $\mathrm{NK}$ cell survival, proliferation, cytotoxicity, and cytokine production, including IFN- $\gamma$ (80). Therefore, NK cells are uniquely equipped to sense and quickly respond to viral infections.

\section{NK Cell Effector Functions and Memory}

NK cells are found in circulation and in peripheral tissues (63) and can be quickly recruited to sites of infection where they facilitate and accelerate viral clearance. In fact, NK cells are not thought to have permanent tissue residency but instead move dynamically between the blood and tissues, such as the lungs (83). NK recruitment is regulated by chemokine gradients that are sensed via chemokine receptors $(84,85)$. Activated NK cells induce the apoptosis of target cells through the engagement of death receptors, such as TRAIL and Fas (86) or via direct cytotoxicity through $\mathrm{Ca}^{2+}$-dependent exocytosis of cytolytic granules (perforin and granzymes) (87). Moreover, NK cells secrete cytokines, including IFN- $\gamma$, which have key anti-viral properties (88).

In addition to being essential first responders to viral infection, NK cells can elicit a stronger secondary response resembling the memory features of adaptive lymphocytes $(89,90)$. NK cell memory has been initially described in mice infected by MCMV, where $\mathrm{Ly}_{4} 9 \mathrm{H}^{+} \mathrm{NK}$ cells quickly expand and have stronger responses after a secondary encounter with the virus (91). Interestingly, a similar NK cell subset has been identified in humans, where NK cells expressing NKG2C are expanded and persist in CMV infected patients (92). Both Ly49H and NKG2C bind viral determinants, highlighting how NK cell memory is linked with the ability of NK cells to directly recognize viruses $(93,94)$. In addition to direct recognition of viral molecules, longlasting changes in NK cells are induced by the cytokine milieu $(89,95)$, which can be elicited by viral infection.

\section{NK Cell Dysfunction Is Linked With Increased Viral Susceptibility}

The relevance of NK cells in fighting viral infections has been highlighted by several studies where NK cells, in mice and humans, were not present or had compromised functions (96). For example, individuals with NK cell deficiencies (NKD), a subset of primary immunodeficiency diseases, are highly susceptible to viral infection, particularly by herpesvirus and papillomavirus families (96). The seminal 1989 case of NKD in an adolescent female with severe herpesvirus infections (varicella pneumonia, disseminated CMV, and disseminated HSV) revealed how functional NK cell deficiencies have clinical consequences in terms of viral infections (97). Cancer patients are also at risk of viral infections (98), which may be explained, at least in part, by an impairment of NK cell responses often observed in humans and in murine tumor models (99-104).

Unsurprisingly, cancer patients are at a significantly increased risk of severe COVID-19 $(105,106)$. Elderly patients are also more susceptible to viral infections (107). Mouse studies highlighted how a decreased number of circulating mature NK cells in aged animals paralleled with increased susceptibility to viral infections (108). Studies in humans suggest that although NK cell numbers can actually increase with aging, NK cell activity declines significantly (109, 110). PrzemskaKosicka et al. investigated NK cell function in response to seasonal influenza vaccination in young and old populations and observed quantitative and qualitative changes associated with impaired responses in the NK cell population and this was associated with poor seroconversion in the older population (111). Additionally, obesity, which has been shown to cause systemic NK cell dysfunction $(112,113)$, has also been linked to increased COVID-19 severity and could be the reason behind the high prevalence of severe COVID-19 in younger people (113). In short, NKD and individuals with reduced NK cell numbers or function are more susceptible to viral infections. Unsurprisingly, the CDC has already highlighted a higher risk of infection and severity of COVID-19 in older individuals and individuals with comorbidities such as obesity and cancer (114). However, this point is still controversial as a systematic review showed that primary immunodeficiencies are not linked with increased COVID-19 severity (115), but these data have to be interpreted keeping in mind that a large part of COVID-19 pathology is caused by excessive immune activation, which is arguably harder to reach in immunocompromised individuals. 
Given the paradoxical role of the immune response in COVID19 patients, it would be extremely useful to be able to rely on immunological functional biomarkers that could predict the outcome of disease severity. Such assays are readily available for determining NK cell activity, e.g., $\mathrm{NKVue}^{\mathrm{TM}}$, and there is therefore an opportunity to conduct studies that would link NK cell functions to disease severity.

\section{NK CELLS AND CORONAVIRUS INFECTIONS: DUAL ROLES}

\section{Coronaviruses Potently Suppress Type I IFN Responses}

Evasion of host immune responses is necessary for the successful propagation of a virus. Mechanisms employed by CoVs to evade the immune response could provide insights into how the immune system, and NK cells in particular, responds to SARS-CoV-2. CoVs have been shown to target components of the innate IFN response, employing non-structural proteins (nsps), structural proteins, and accessory proteins to achieve this goal. Nsp16 methylates viral RNA therefore preventing recognition by MDA5 and dampening type I IFN production (116). Nsps also suppress type I IFN responses via the inhibition of the transcription factor STAT1 mRNA transcription (nsp1) and deubiquitination of transcription factors like Interferon Regulatory Transcription Factor (IRF)3 (nsp3) (116). Moreover, viral-encoded accessory proteins from SARS-CoV-1 open reading frame (ORF)3b and MERS-CoV ORF4a/4b also block IFN production and signaling (116). In addition, the MERS-CoV ORF6-encoded protein blocks p-STAT1 import, thus blocking IFN signaling (116). Finally, the structural M protein of MERS$\mathrm{CoV}$ (27) physically sequesters kinase proteins RIG-I, TBK1, IKKe, and TRAF3 and the SARS-CoV-1N protein inhibits Activator Protein (AP)-1 signaling, protein kinase $\mathrm{R}$ function, and NFKB activation, all of which act to impede IFN responses (117). In vivo murine studies report young mice rapidly clear SARS-CoV-1 infection, while old mice do not and that this discrepancy is due to a delay in type I IFN. Furthermore, early administration of IFN- $\beta$ induces a stronger immune response and reduces mortality in old mice (118). Since type I IFNs are critical for NK cell activation and effector functions, it is possible that NK cell-mediated clearance of SARS-CoV-2 is being subverted by these mechanisms. Further research into the role of NK cells in CoV clearance and potential immune evasion mechanisms are necessary to inform therapeutic development and use.

\section{NK Cell Role in Clearing Acute Coronavirus Infections}

There is currently a paucity of studies into the role of NK cells not only in COVID-19 pathophysiology, but also in other coronavirus infections. An in vivo study reported that beige mice on a B6 background cleared SARS-CoV-1 normally, indicating that functional lymphocytes, including NK cells, may not be required to eliminate SARS-CoV-1 in murine models (119). However, in a more recent study characterizing the cellular immune response to SARS-CoV-1 in 12-14-month old BALB/c mice, $\mathrm{T}$ cell depletion did not prevent control of SARS-CoV1 replication (120), suggesting a role for the innate immune system, and NK cells, in viral clearance. Importantly, in this study CD4-depletion resulted in enhanced lung immunopathology and delayed viral clearance, while CD8-depletion did not affect viral replication or clearance, thus highlighting an important role for $\mathrm{CD}^{+} \mathrm{T}$ cells in coronavirus infection. These conflicting results may be due to the inherent limitations of $\mathrm{CoV}$ murine models. In 4-8 week-old mice, SARS-CoV-1 is associated only with mild pneumonitis and cytokines are not detectable in the lungs $(119,121,122)$. A SARS-CoV-1 isolate (MA-15) replicates to a high titer and is associated with viremia and mortality, however the model lacks significant inflammatory cell infiltration into the lungs (123). Thus, mouse models developed for the study of SARS fell short in terms of reproducing the clinical and histopathological signs of disease $(119,121-123)$. It is therefore necessary to develop a usable animal model that is capable of reproducing the clinical and histopathological signs on COVID-19. Israelow et al. recently described a SARS-CoV-2 murine model based on adeno associated virus (AAV)9-mediated expression of human (h)ACE2, which replicated the pathologic findings found in COVID-19 patients (124). This model, which overcame the inability of murine (m)ACE2 to support SARSCoV-2 infection, was used to show the inability of Type I IFN to control SARS-CoV-2 replication (124). In a similar attempt to overcome the lack of infectability through mACE2, Dinnon et al. recently described a recombinant virus (SARS-CoV-2 MA) with a remodeled $S$ protein $\mathrm{mACE} 2$ interface, which replicated in upper and lower airways in young and aged mice with disease being more severe in aged mice. The authors used this model to screen therapeutics from vaccine challenge studies and assessed pegylated IFN- $\lambda-1$ as a promising therapeutic. The authors suggested that this model has greater ease of use, cost, and utility over transgenic hACE2 models (125) to evaluate vaccine and therapeutic efficacy in mice (126).

A preliminary analysis of NK cell function and phenotype has been performed by Zheng et al. using peripheral blood from COVID-19 patients (127). On admission, NK cell levels in the peripheral blood inversely correlated with disease severity. Furthermore, COVID-19 patients with severe disease had significantly lower numbers of circulating NK cells, as compared to mild disease $(p<0.05)$ (127). Additionally, circulating NK cells in severe disease displayed increased expression of the inhibitory receptor NKG2A and had an hyporesponsive phenotype with lower levels of IFN- $\gamma$, tumor necrosis factor (TNF)- $\alpha$, IL-2, and granzyme B, although degranulation was maintained (127). Finally, as compared to patients with active disease, patients recovering from COVID-19 had higher numbers of NK cells and lower NKG2A expression (127). Liao et al. performed singlecell RNAseq on the cells obtained from bronchoalveolar lavage fluid of severe and mild COVID-19 patients and found that COVID-19 patients had significantly more NK cell infiltrates into the lungs, however patients with severe disease had reduced proportions of NK cells (128). In addition, KLRC1 (NKG2A) and KLRD1 (CD94) were highly expressed by NK cells (128). Carvelli et al. analyzed myeloid and lymphoid populations by 
immunophenotyping from blood and bronchoalveolar lavage fluid (BALF) in 10 healthy controls, 10 paucisymptomatic COVID-19 patients, 34 pneumonia patients, and 28 patients with ARDS due to SARS-CoV-2 and found that absolute numbers of peripheral blood lymphocytes, including NK cells, were significantly reduced in the pneumonia and ARDS groups compared to healthy controls. Furthermore, the proportion of mature NK cells was reduced in patients with ARDS and NK cells showed increased NKG2A, PD-1, and CD39 (129). Finally, Wilk et al. performed single-cell RNA-sequencing on 7 COVID19 patients and 6 healthy controls and found that the CD56 bright population was depleted in all COVID-19 patients but the CD56 ${ }^{\mathrm{dim}}$ population was depleted only in patients with severe COVID-19. Furthermore, NK cells had increased expression of the exhaustion markers LAG3 and HAVCR2 (130). NK cell cytopenia seems to be a consistent characteristic among SARSCoV-2 infected patients (131). Altogether, these data indicate alterations in the NK cell phenotype and functional profile that are consistent with the hypothesis that to establish a productive and lasting infection, SARS-CoV-2 needs to dampen the NK cell response.

NK cell dysfunctions were also observed in patients from the previous CoV outbreaks. Wang et al. assessed NK cell number and phenotype using peripheral blood from 221 SARS patients admitted to hospitals in Beijing, China (132). NK cell proportion and absolute number were significantly reduced in SARS patients as compared to healthy donors and patients infected with the bacterium Mycoplasma pneumoniae (131). NK cell number correlated inversely with disease severity and patients with antiSARS CoV-specific IgG or IgM antibodies had significantly fewer NK cells (132). The patients assessed had varied disease duration from 4 to 72 days (mean 31.7 days) and this allowed for patient stratification by disease duration. Within the first 10 days of SARS-CoV-1 infection, NK cell numbers remained high but this period was followed by the development of lymphopenia with levels recovering only around day 40 (132). Dong et al. also observed a reduction of NK cell numbers in SARS patients, and these levels were lower in patients with severe, as compared to mild, SARS (133). In addition, MERS infection is strongly associated with leuko- and lymphopenia (42, 134-136).

The mechanisms underlying the reduction of circulating NK cells in patients infected with CoVs are still unclear. As most studies have focused on peripheral blood NK cells, it is possible that the reduced number of circulating $\mathrm{NK}$ cells is due to redistribution of blood NK cells into the infected tissues (137). While it is hard to assess NK cell migration to infected tissues in COVID-19 patients, this hypothesis was corroborated by mouse studies, where NK cells have been shown to migrate to the lungs in CoV infected animals (120).

An abundance of inhibitory factors, such as TGF- $\beta$, may be partially responsible for the NK cell hyporesponsiveness observed in COVID-19 patients. In support of this hypothesis, Huang et al. found significantly higher TGF- $\beta$ levels in SARS patients compared to healthy controls and this positively correlated with length of stay (138). Given the importance of TGF- $\beta$ in suppressing NK cell functions, it is possible that the higher levels of TGF- $\beta$ (as well as other inhibitory cytokines) in CoV patients leads to suppression of NK cell antiviral activity (138). Early studies of COVID-19 patients report secondary (super-) infections, including nosocomial pneumonia or bacteremia as a complication of SARS-CoV-2 infection (138). Since NK cells are critical first responders that play a role in preventing and clearing infections (139), a poor NK cell count or exhausted phenotype, in addition to negatively influencing COVID-19 patient outcomes, could facilitate the development of secondary infections and have a significant negative impact on patient outcomes.

One of the main barriers in studying the role of NK cell activation in the early clearance of $\mathrm{CoV}$ infection in asymptomatic or mildly symptomatic patients is the fact that these individuals are rarely diagnosed in the clinic and therefore an opportunity to collect samples for research does not exist. Thus, while there is currently no direct evidence to support a role for NK cells in the clearance of SARS-CoV-2, evidence showing that viral infection has a negative effect on the NK cell compartment is accumulating. Given the importance of NK cell activity in early viral clearance and late immunopathology, having a rapid and reliable test to predict NK cell function, such as $\mathrm{NKVue}^{\mathrm{TM}}$ (ATGen Canada/NKMax), whereby whole blood is stimulated by an NK cell-specific activating cytokine mix and activity is measured via IFN- $\gamma$ production, might allow researchers to predict who will mount an adequate response with asymptomatic or minimally symptomatic viral clearance and who will need ICU admission, as has been shown with cancer patients (140). Further research will be required into the innate immune response to $\mathrm{CoV}$ infection to more fully understand NK cell contributions to viral clearance.

\section{NK Cell Role in Coronavirus Immunopathology}

In the context of CoVs, the significant morbidity and mortality associated with severe disease is due to acute lung injury (ALI) and the development of ARDS $(19,141)$. Pathological analysis of tissues obtained from SARS and MERS patients showed edematous lungs with areas of consolidation, bronchial epithelial denudation, loss of cilia, squamous metaplasia, pneumocyte hyperplasia, and bronchial submucosal gland necrosis (19, 29). Histological features include diffuse alveolar damage and acute fibrinous and organizing pneumonia (29). A heightened inflammatory response in the lungs resulting in tissue damage has been hypothesized to explain the development of ALI.

There are several key factors that may be responsible for the induction of this dangerous inflammation (138). Both SARSCoV-1 and MERS-CoV replicate to high titers early in infection, which could lead to enhanced cytopathic effects and increased production of pro-inflammatory cytokines/chemokines by infected cells. Chen et al. developed a pneumonia model where pulmonary replication of SARS-CoV-1 was associated with histopathological evidence of disease, including bronchiolitis, interstitial pneumonitis, diffuse alveolar damage, and fibrotic scarring (120). They identified a biphasic cellular immune response in which cytokines (TNF- $\alpha$ and IL-6) and chemokines [interferon gamma-induced protein (IP)-10, monocyte chemoattractant protein (MCP)-1, macrophage inflammatory 
protein (MIP)-1a, RANTES] were produced early, likely by infected airway epithelial cells, alveolar macrophages, and recruited inflammatory monocyte-macrophages and neutrophils, which have been shown to replace resident alveolar macrophages $(19,142)$. SARS-CoV-1 and MERS-CoV encode structural and non-structural proteins that antagonize the interferon response, which may initially delay the innate immune response but eventually potentiate inflammatory monocyte-macrophage responses (19). In COVID-19 patients, Liao et al. reported increased lung infiltration by macrophages identified via RNAseq analysis of bronchoalveolar lavage fluid. Patients with mild cases exhibited infiltration by alveolar macrophages [Fatty Acid Binding Protein (FABP $) 4^{+}$] while patients with severe ARDS exhibited infiltration by highly inflammatory [Ficolin $(\mathrm{FCN1})^{+}$] monocyte-derived macrophages (128).

In the SARS-CoV-1 pneumonia model, the first wave of cytokines and chemokines induced an accumulation of NK cells, as well as plasmacytoid (p)DCs, macrophages, CD4 ${ }^{+} \mathrm{T}$ cells and NKT cells in the lungs. A second wave of inflammatory mediators was detected later on day 7 post-infection [cytokines TNF- $\alpha$, IL-6, IFN- $\gamma$, IL-2, IL-5, and chemokines MCP-1, MIP1a, RANTES, monokine induced by gamma interferon (MIG), IP-10] and correlated with lung infiltration of $\mathrm{T}$ cells and neutrophils (120). These findings are consistent with studies that have shown increased levels of activating and inhibitory cytokines and chemokines in the blood and lungs of SARS patients, as well as histological studies of SARS and MERSinfected lungs which show extensive cell infiltrates (19, 29, 143145). When Huang et al. investigated the cytokine/chemokine profile in the acute phase of SARS infection in a cohort of Taiwanese patients, they observed an IFN- $\gamma$-led cytokine storm (138). They assessed sera from hospitalized patients prior to the administration of immunomodulators and found significantly increased levels of IFN- $\gamma$, IL-18, IP-10, MCP-1, MIG, and IL-8 (138), which returned to basal levels in convalescent sera. IP-10, MIG, MCP-1, and IL-18 levels were all significantly increased in death vs. survival groups. Interestingly, they found an inverse relationship between IFN- $\gamma$ levels and lymphocyte numbers and suggested this could either be due to IFN- $\gamma$-induced lymphocyte apoptosis or sequestration of chemokine-recruited lymphocytes in the lungs (138). Indeed, this hyper-cytokinemia has been consistently observed in SARS-infected patients (146). However, a recent study found that levels of six pro-inflammatory cytokines (IL-1b, IL-1Ra, IL-6, IL-8, IL-18, and TNF- $\alpha$ ) implicated in the cytokine storm in COVID-19 patients did not differ significantly from levels in cytokine storms caused by other conditions. They suggest that it is therefore possible that increased levels of proinflammatory cytokines in the context of severe COVID-19 may simply reflect an increased viral burden rather than an exuberant immune response and suggest that immunotherapies should therefore be used with caution (147).

Altogether these studies show that during acute $\mathrm{CoV}$ infection, inflammatory monocyte-macrophages and neutrophils accumulate in the lungs and produce cytokines and chemokines that induce the activation and migration of lymphocytes, including NK cells, to the lungs, where they could be one of the main producers of IFN- $\gamma$ (148). Under normal conditions, human lung NK cells are typically hyporesponsive but dynamically migrate in and out of pulmonary tissues (83). This supports the hypothesis that during infectious respiratory diseases, an increased recruitment of hyperresponsive NK cells would worsen the festering immunopathology (8). In fact, through Viral-Track scanning of unmapped single-cell RNAsequencing data, Bost et al. showed that patients with severe COVID-19 exhibited a hyperinflammatory response with an enriched and highly proliferative NK cell compartment (142). High levels of IFN- $\gamma$ leads to epithelial and endothelial cell apoptosis and vascular leakage, suboptimal $\mathrm{T}$ cell response, accumulation of alternatively activated macrophages and altered tissue homeostasis, and ARDS (19), all of which may contribute to COVID-19 disease severity. In summary, the evidence is consistent with the hypothesis that NK cells are involved in the cytokine storm associated with $\mathrm{CoV}$ infection and that this hyper-cytokinemia contributes significantly to disease severity via inflammation-mediated lung damage (Figure 1).

Interestingly, this duality of NK cell roles mirrors what is seen in critically ill patients with sepsis. Studies suggest that while early NK cell stimulation and IFN- $\gamma$ production is beneficial to combat infections, excessive and prolonged stimulation of NK cells leads to reduced NK cell numbers and an exhausted phenotype and was associated with increased systemic inflammation in systemic inflammatory response syndrome (SIRS)/sepsis and increased mortality (149-152).

This review of the literature suggests that NK cells may play an important role in both $\mathrm{CoV}$ clearance and immunopathology. The continued probing of NK cell involvement is essential for a more complete understanding of $\mathrm{CoV}$ pathophysiology and for the deployment of immunotherapeutics. Depending on the patient, the stage of disease, and other still poorly understood factors, it may be necessary to either boost NK cell activity to ensure viral clearance, e.g., at exposure or during early infection, or to finely tune NK cell effector functions in late stage infections to prevent hyper-cytokinemia and inflammatory lung damage. Indeed, all CoVs that infect humans are zoonoses and there is an extensive reservoir of CoVs that could serve as a source for future pandemics $(14,153)$. Therefore, a broader understanding of the immune response to coronaviruses and insights into therapeutic implications will be of significant value not only for the current COVID-19 pandemic, but also for potential future pandemics.

\section{FLATTENING THE CURVE WITH NATURAL KILLER CELLS}

The race to vaccinate and find a cure for COVID-19 has resulted in a spectacular effort from researchers and medical practitioners around the world. Early attempts at creating targeted therapeutics have mostly relied on historical evidence from related, but not identical, coronaviruses and on the paucity of studies investigating SARS-CoV-2. These strategies have attempted to combat the virus by targeting various stages of its life cycle starting with neutralizing SARS-CoV-2 virions using monoclonal antibodies or plasma from convalescent patients (154). The entry mechanism of CoVs has been shown to rely 


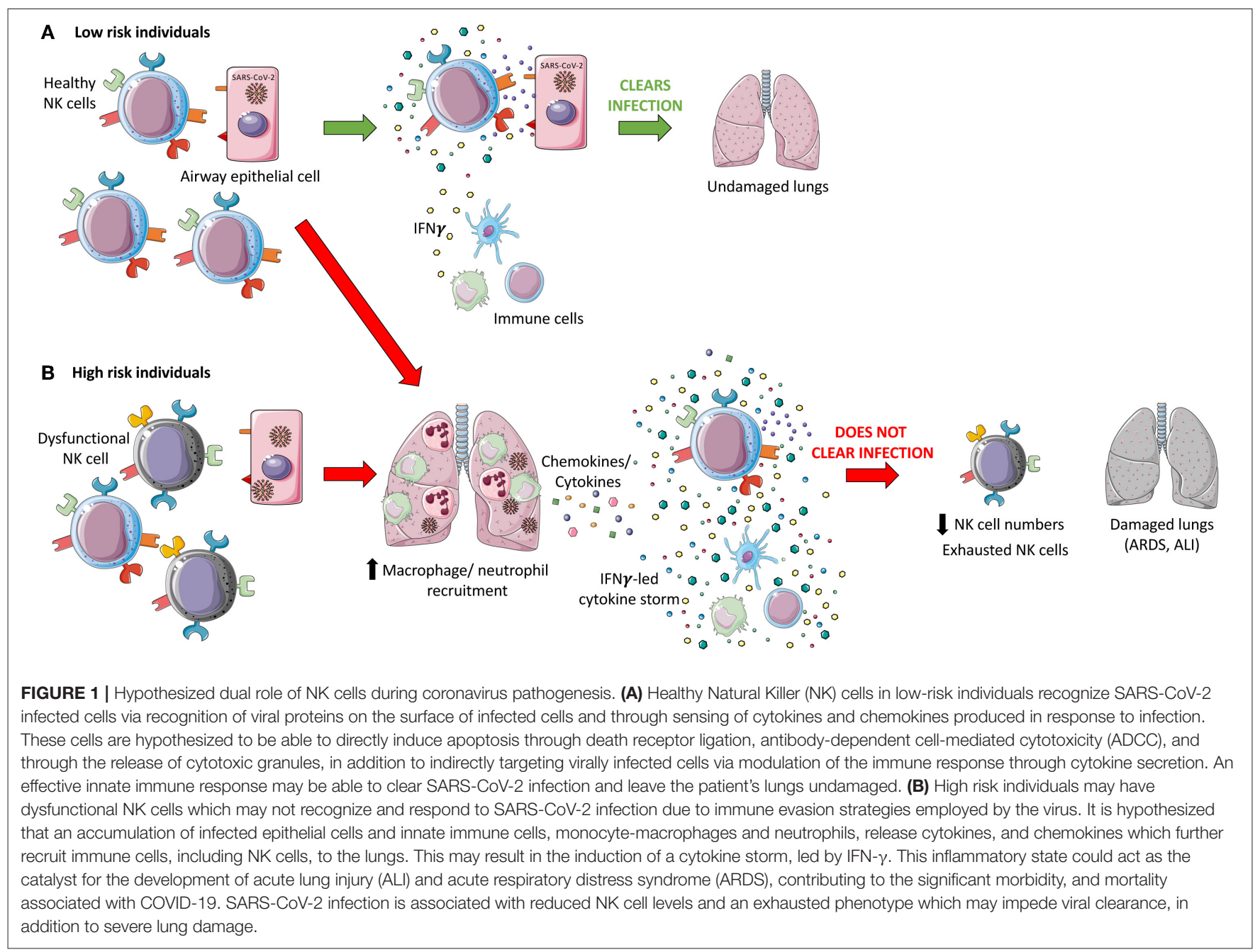

on binding the ACE2 receptor and using proteases such as TMPRSS2 for S protein priming (52). Thus, preventing ACE2 receptor binding through blocking antibodies or competitive binding with soluble ACE2 and TMPRSS2 protease inhibitors (Camostat mesylate) are being tested (155). Upon viral entry, the viral proteolysis or replication cycle can be targeted with protease inhibitors (Lopinovir and Ritonavir) (156) or RNA-dependent RNA polymerase inhibitors (Remdesivir and Ribavirin) (157). At the time of writing this review, the results of these trials have not been released or are still preliminary and will require further evaluation to assess their clinical efficacy in larger cohort studies. As NK cell activity is critical for viral clearance and may be involved in disease immunopathology, a rapid and reliable predictor of NK cell function may allow for the prediction of clinical progression and the stratification of patients to receive therapeutic intervention. The remainder of this review will discuss the various ways immunotherapies are being deployed to tackle COVID-19, with a focus on therapies that use NK cells (Table 1). Lastly, while NK cells play an important role in combating viral infections, we also need to be fully cognizant of the potential damage immunotherapies could have in severe cases of COVID-19, and how these adverse effects may need to be attenuated (Table 2).

\section{NK Cell-Based Products}

In the absence of a clinically approved vaccine against SARS$\mathrm{CoV}-2$, scientists have begun developing therapeutics to halt the spread of COVID-19 by alternative strategies. Studies have reported that patients infected with SARS-CoV-2 have lower levels of circulating NK cells and these express a greater level of inhibitory receptors (e.g., NKG2A) while producing less IFN- $\gamma$ $(127,129,130)$. These findings provide a rationale for pursuing NK cell-based therapies as a tool to fight COVID-19. Although NK cell-based therapies have mostly been developed for use against cancer, similar concepts and mechanisms could provide guidance in the fight against viruses.

Therapeutic NK cell products can be thought of as "living drugs" as they generally use either primary NK cells isolated from peripheral blood mononuclear cells (PBMCs) or are generated from stem cell precursors or genetically engineered immortalized human NK cell lines (158). Primary NK cell products are often pre-treated and expanded in vitro with cytokines or via co-culture 
TABLE 1 | List of COVID-19 clinical trials using immunomodulatory therapies.

\begin{tabular}{|c|c|c|c|c|c|c|c|}
\hline Category & Therapeutic(s) & Trial identifier & Phase & $\begin{array}{l}\text { Location } \\
\text { (centers) }\end{array}$ & $\begin{array}{l}\text { Patients } \\
\text { (n) }\end{array}$ & Study eligibility & Mechanism of action(s) \\
\hline \multicolumn{8}{|c|}{ NK cell-based products } \\
\hline \multirow[t]{3}{*}{ Adoptive NK cells } & NK cells & NCT04280224 & I & Henan, China & 30 & $\begin{array}{l}\text { Pneumatic } \\
\text { COVID19+ }\end{array}$ & Adoptive NK cell therapy \\
\hline & CYNK-001 & NCT04365101 & $\mid / I I$ & New Jersey, USA & 86 & Mild COVID19+ & $\begin{array}{l}\text { From human placental } \\
\text { CD34+ cells and } \\
\text { culture-expanded }\end{array}$ \\
\hline & $\begin{array}{l}\text { NK cells isolated from healthy } \\
\text { donor PBMCs }\end{array}$ & NCT04344548 & $\mid / I I$ & $\begin{array}{l}\text { Bagota, } \\
\text { Colombia }\end{array}$ & 10 & NEWS of $>4$ & $\begin{array}{l}\text { Isolated NK cells ex vivo } \\
\text { stimulated with IL-2 and IL-15 }\end{array}$ \\
\hline CAR-NK Cells & $\begin{array}{l}\text { NKG2D-ACE2 CAR-NK cell } \\
\text { therapy from umbilical cord } \\
\text { blood }\end{array}$ & NCT04324996 & $\mid / I I$ & $\begin{array}{l}\text { Chongqing, } \\
\text { China }\end{array}$ & 90 & Within <14 dpi & $\begin{array}{l}\text { IL-15 prolongs NK cell } \\
\text { lifespan; GM-CSF neutralizing } \\
\text { scFV reduces recruitment of } \\
\text { inflammatory cells; } \\
\text { NKG2D-ACE2 CAR-NK cells } \\
\text { can target virally infected } \\
\text { cells; ACE2 CAR-NK can act } \\
\text { as decoy cell }\end{array}$ \\
\hline \multicolumn{8}{|c|}{ NK cell immunostimulants } \\
\hline \multicolumn{8}{|c|}{ Direct NK cell activation } \\
\hline \multirow[t]{4}{*}{ IFN- $\alpha$ Therapy } & $\begin{array}{l}\text { Recombinant human IFN- } \alpha \pm \\
\text { Thymosin alpha } 1\end{array}$ & NCT04320238 & III & Hubei, China & 2,944 & Uninfected HCW & $\begin{array}{l}\text { IFN-alpha boosts immune } \\
\text { system; thymosin alpha } 1 \\
\text { activates TLRs in myeloid and } \\
\text { pDCs leading to NK cell } \\
\text { activation }\end{array}$ \\
\hline & Recombinant human IFN- $\alpha 2 \beta$ & NCT04293887 & 1 & Hubei, China & 328 & Within $<7$ dpi & $\begin{array}{l}\text { IFN-alpha activates interferon } \\
\text { pathway }\end{array}$ \\
\hline & $\begin{array}{l}\text { Abidol Hydrochloride } \pm \text { IFN } \\
\text { atomization (Peg-IFN- } \alpha-2 b)\end{array}$ & NCT04254874 & IV & Hubei, China & 100 & $\begin{array}{l}\text { Pneumatic } \\
\text { CovID19+ }\end{array}$ & \\
\hline & $\begin{array}{l}\text { Rintatolimod } \pm \text { Recombinant } \\
\text { IFN- } \alpha 2 \beta\end{array}$ & NCT04379518 & $\mid / I I$ & New York, USA & 80 & $\begin{array}{l}\text { Mild to moderate } \\
\text { COVID19+ }\end{array}$ & \\
\hline \multirow[t]{4}{*}{ IFN- $\beta$ Therapy } & Lopinavir/ritonavir \pm IFN- $\beta$-1a & NCT04315948 & III & France (3) & 3,100 & Moderate/Severe & $\begin{array}{l}\text { IFN-beta activates interferon } \\
\text { pathway }\end{array}$ \\
\hline & Base therapy $\pm \mathrm{IFN}-\beta-1 \mathrm{a}$ & NCT04350671 & IV & Tehran, Iran & 40 & Within $<10$ dpi & $\begin{array}{l}\text { Base therapy }= \\
\text { Hydropinchloroquine }+ \\
\text { Lopinavir/Ritonavir }\end{array}$ \\
\hline & Base therapy $\pm \mathrm{IFN}-\beta-1 \mathrm{~b}$ & NCT04276688 & $\|$ & Hong Kong, HK & 127 & NEWS of $\geq 1$ & $\begin{array}{l}\text { Base therapy }= \\
\text { Lopinavir/ritonavir/Ribavirin }\end{array}$ \\
\hline & $\begin{array}{l}\text { IFN- } \beta-1 \text { a vs. IFN- } \beta-1 \mathrm{~b} \text { (+Base } \\
\text { therapy) }\end{array}$ & NCT04343768 & IV & Tehran, Iran & 60 & Moderate/Severe & $\begin{array}{l}\text { Base therapy }= \\
\text { Hydropinchloroquine }+ \\
\text { Lopinavir/Ritonavir }\end{array}$ \\
\hline \multicolumn{8}{|c|}{ Indirect NK cell activation } \\
\hline \multirow[t]{5}{*}{ IFN- $\lambda$ Therapy } & Peg-IFN-Lambda-1a & NCT04331899 & $\|$ & California, USA & 120 & Early COVID19+ & $\begin{array}{l}\text { IFN-lambda to boost NK cells } \\
\text { indirectly through Monocytes, } \\
\text { Macrophages, and pDCs } \\
\text { IL-12 secretion }\end{array}$ \\
\hline & Peg-IFN-Lambda-1a & NCT04343976 & $\|$ & Boston, USA & 40 & Early COVID19+ & \\
\hline & Peg-IFN-Lambda-1a & NCT04354259 & $\|$ & Toronto, Canada & 140 & $\begin{array}{l}\text { Ambulatory and } \\
\text { hospitalized }\end{array}$ & \\
\hline & Peg-IFN-Lambda-1a & NCT04388709 & $\|$ & New York, USA & 66 & $\begin{array}{l}\text { Non-ICU } \\
\text { COVID19+ }\end{array}$ & \\
\hline & Peg-IFN-Lambda-1a & NCT04344600 & $\|$ & Maryland, USA & 164 & $\begin{array}{l}\text { Asymptomatic } \\
\text { COVID19+ }\end{array}$ & \\
\hline \multicolumn{8}{|c|}{ Immunoregulatory therapies } \\
\hline $\begin{array}{l}\text { Immune } \\
\text { checkpoint } \\
\text { blockade }\end{array}$ & Anti-PD-1 (vs. Thymosin) & NCT04268537 & $\|$ & Nanjing, China & 120 & $\begin{array}{l}\text { Respiratory failure } \\
\text { within }<48 \text { h of } \\
\text { ICU }\end{array}$ & $\begin{array}{l}\text { Prevent T-cell regulation by } \\
\text { blocking PD-1; in COVID19+ } \\
\text { advanced or metastatic } \\
\text { cancer patients; }\end{array}$ \\
\hline
\end{tabular}


TABLE 1 | Continued

\begin{tabular}{|c|c|c|c|c|c|c|c|}
\hline Category & Therapeutic(s) & Trial identifier & Phase & $\begin{array}{l}\text { Location } \\
\text { (centers) }\end{array}$ & $\begin{array}{l}\text { Patients } \\
(n)\end{array}$ & Study eligibility & Mechanism of action(s) \\
\hline & $\begin{array}{l}\text { Anti-PD-1 (pembrolizumab) }+ \\
\text { tocilizumab }\end{array}$ & NCT04335305 & $\|$ & Nanjing, China & 24 & $\begin{array}{l}\text { Pneumatic } \\
\text { COVID19+ }\end{array}$ & Tocilizumab $=$ anti-IL-6R \\
\hline & $\begin{array}{l}\text { Anti-PD-1 (nivolumab) vs. } \\
\text { GNS651 }\end{array}$ & NCT04333914 & $\|$ & France (4) & 273 & Early COVID19+ & $\begin{array}{l}\text { GNS651 = Chloroquine } \\
\text { analog }\end{array}$ \\
\hline \multicolumn{8}{|c|}{ Non-specific innate immune stimulation } \\
\hline \multirow{3}{*}{$\begin{array}{l}\text { Heterologous } \\
\text { vaccines }\end{array}$} & BCG (Danish strain) & NCT04327206 & III & Australia (8) & 4,170 & Uninfected HCW & \\
\hline & BCG (Danish strain) & NCT04350931 & III & Egypt & 900 & Uninfected HCW & \\
\hline & BCG (Danish strain) & NCT04379336 & III & South Africa & 500 & $\mathrm{HCW}$ & \\
\hline TLR agonists & PUL-042 (CpG ODN) & NCT04312997 & $\|$ & Texas, USA & 100 & Within $<7$ dpi & \\
\hline \multicolumn{8}{|c|}{ Natural health products and alternative medicines } \\
\hline \multirow[t]{8}{*}{ Vitamins } & Vitamin C & NCT04323514 & $\mathrm{N} / \mathrm{A}$ & Palermo, Italy & 500 & $\begin{array}{l}\text { Pneumatic } \\
\text { COVID19+ }\end{array}$ & $\begin{array}{l}\text { General immune boosting } \\
\text { properties of vitamin } C \text { and } \\
\text { natural health products }\end{array}$ \\
\hline & Vitamin C & NCT04264533 & $\|$ & Hubei, China & 140 & ICU COVID19+ & \\
\hline & Vitamin C & NCT03680274 & III & Quebec, Canada & 800 & ICU COVID19+ & \\
\hline & Vitamin C & NCT04344184 & $\|$ & Virginia, USA & 200 & ICU COVID19+ & \\
\hline & Vitamin C + Zinc & NCT04342728 & N/A & Ohio, USA & 520 & $\begin{array}{l}\text { Outpatient } \\
\text { CovID19+ }\end{array}$ & \\
\hline & $\begin{array}{l}\text { Hydroxychloroquine; } \\
\text { Azithromycin; Vitamin C, D; } \\
\text { and Zinc }\end{array}$ & NCT04334512 & $\|$ & California, USA & 600 & $\begin{array}{l}\text { Low risk } \\
\text { COVID-19+ }\end{array}$ & \\
\hline & $\begin{array}{l}\text { Zinc + Vitamin D } \\
\text { (cholecalciferol) }\end{array}$ & NCT04351490 & N/A & Lille, France & 3,140 & $\begin{array}{l}\text { Asymptomatic } \\
\text { COVID19+ }\end{array}$ & $\begin{array}{l}\text { To treat zinc and vitamin D } \\
\text { deficiency and reduce } \\
\text { inflammation and ARDS }\end{array}$ \\
\hline & High dose Vitamin D (4X) & NCT04344041 & III & France (9) & 260 & $\begin{array}{l}\text { Severe } \\
\text { COVID19+ }\end{array}$ & \\
\hline
\end{tabular}

NEWS, National Early Warning Score; HCW, Healthcare Workers; Peg, pegylated; dpi, days post-infection; As of June 1, 2020.

with target cells before being infused into patients. Patients can also receive immune stimulants [e.g. recombinant IL-2 (159) or IL-15 (160)] with the goal of improving the in vivo activity and persistence of the NK cell products (161) as is being tested in this COVID-19 trial (NCT04344548). The first cell-based investigational drug to be approved by the FDA for clinical testing in COVID-19 patients is an allogeneic, off-the-shelf, cryopreserved NK cell therapy made by Celularity (CYNK-001), originally developed for cancer immunotherapy (162). The trial (NCT04365101) is split into two Phases. Phase I will assess the frequency and severity of adverse events in mild, non-ICU COVID-19 patients $(n=14)$ following infusion of NK cells derived from placental CD34 ${ }^{+}$cells. The subsequent Phase II trial will recruit up to 72 patients and include a standard of care comparator at a 1:1 allocation.

Genetically modified NK cells are also being investigated for efficacy against COVID-19. Chimeric antigen receptor NK cells (CAR-NK cells) are engineered to express virtually any receptor(s) of interest and were originally designed to enhance the ability of NK cells to eliminate cancer cells via receptors targeting EGFR (163) or CD19 (164), which are present on many cancer types and B cell hematological malignancies, respectively (164). Although the efficacy of CAR-NK cells to control viral infections has yet to be rigorously tested in large scale clinical 
TABLE 2 | List of COVID-19 clinical trials investigating immunotherapies for mitigating immunopathology.

\begin{tabular}{|c|c|c|c|c|c|c|c|}
\hline Category & Therapeutic(s) & Trial identifier & Phase & $\begin{array}{l}\text { Location } \\
\text { (centers) }\end{array}$ & Patients $(\boldsymbol{n})$ & Study eligibility & Mechanism of action(s) \\
\hline \multicolumn{8}{|c|}{ Anti-cytokine therapy } \\
\hline \multirow[t]{18}{*}{ Anti IL-6 } & Tocilizumab & NCT04315480 & $\|$ & Italy & 38 & Pneumatic COVID19+ & $\begin{array}{l}\text { Anti-IL6R mAB to prevent } \\
\text { virus-related cytokine storm and } \\
\text { reduce symptoms of } \\
\text { severe COVID-19 }\end{array}$ \\
\hline & Tocilizumab & NCT04317092 & $\|$ & Italy (27) & 400 & Pneumatic COVID19+ & \\
\hline & Tocilizumab & NCT04320615 & III & Not listed & 330 & Pneumatic COVID19+ & \\
\hline & Tocilizumab & NCT04332913 & $\mathrm{N} / \mathrm{A}$ & Italy & 30 & Pneumatic COVID19+ & \\
\hline & Tocilizumab & NCT04335071 & $\|$ & Switzerland (3) & 100 & Pneumatic COVID19+ & \\
\hline & Tocilizumab & NCT04322773 & $\|$ & Denmark (2) & 200 & Pneumatic COVID19+ & I.V. vs. S.C. routes of administration \\
\hline & Tocilizumab & NCT04331795 & $\|$ & Illinois, USA & 50 & $\begin{array}{l}\text { COVID19+, not on } \\
\text { ventilator }\end{array}$ & $\begin{array}{l}\text { Low }(80 \mathrm{mg}) \text { vs. standard dose } \\
(200 \mathrm{mg}) \text { in non-critically ill patients }\end{array}$ \\
\hline & Tocilizumab & NCT04346355 & $\|$ & Italy (24) & 398 & $\begin{array}{l}\text { Pneumatic COVID19+, } \\
\text { non-ICU }\end{array}$ & $\begin{array}{l}\text { Early administration of tocilizumab on } \\
\text { reduced ventilation time }\end{array}$ \\
\hline & Tocilizumab & NCT04331808 & $\|$ & Paris, France & 240 & $\begin{array}{l}\text { Group 1: non-ICU; Group } \\
\text { 2: ICU }\end{array}$ & \\
\hline & Tocilizumab (vs. CRRT) & NCT04306705 & N/A & Hubei, China & 120 & Pneumatic COVID19+ & $\begin{array}{l}\mathrm{CRRT}=\text { continuous renal } \\
\text { replacement therapy }\end{array}$ \\
\hline & Tocilizumab (vs. Anakinra) & NCT04339712 & $\|$ & Greece (17) & 20 & $\begin{array}{l}\text { Pneumatic COVID19+, } \\
\text { non-ICU }\end{array}$ & Anakinra - IL1r antagonist \\
\hline & Tocilizumab (vs. GNS651) & NCT04333914 & $\|$ & France (4) & 273 & Pneumatic COVID19+ & $\begin{array}{l}\text { Efficacy in COVID19+ advanced or } \\
\text { metastatic cancer patients; GNS651 } \\
=\text { chloroquine analog }\end{array}$ \\
\hline & Sarilumab & NCT04315298 & $\|/\| \|$ & USA (57) & 400 & Pneumatic COVID19+ & Low vs. high dose of sarilumab \\
\hline & Sarilumab & NCT04324073 & $\|/\| I \|$ & France (4) & 239 & $\begin{array}{l}\text { Group 1: non-ICU; Group } \\
\text { 2: ICU }\end{array}$ & \\
\hline & Sarilumab & NCT04327388 & $\|/\| \|$ & $\begin{array}{l}\text { Canada+France } \\
\text { (8) }\end{array}$ & 300 & Pneumatic COVID19+ & \\
\hline & $\begin{array}{l}\text { Hydroxychloroquine }+ \\
\text { Axithromycin } \\
\pm \text { Tocilizumab }\end{array}$ & NCT04332094 & $\|$ & $\begin{array}{l}\text { Barcelona, } \\
\text { Spain }\end{array}$ & 276 & $\begin{array}{l}\text { Early COVID19+, not on } \\
\text { ventilator }\end{array}$ & \\
\hline & Tocilizumab + Favipiravir & NCT04310228 & N/A & China (11) & 150 & COVID19+ & \\
\hline & $\begin{array}{l}\text { Tocilizumab + Anakinra } \\
+ \text { Siltuximab }\end{array}$ & NCT04330638 & III & Belgium (9) & 342 & Pneumatic COVID19+ & $\begin{array}{l}\text { Anakinra - IL 1r antagonist and } \\
\text { Siltuximab - IL6r antagonist }\end{array}$ \\
\hline Anti-IL-8 & Anti-IL-8 (BMS-986253) & NCT04347226 & $\|$ & New York, USA & 138 & Pneumatic COVID19+ & $\begin{array}{l}\text { Prevent recruitment of } \\
\text { inflammatory cells }\end{array}$ \\
\hline \multirow[t]{2}{*}{$\begin{array}{l}\text { Anti IL-1R/Anti } \\
\text { IFN } \gamma\end{array}$} & $\begin{array}{l}\text { Anakinra } \\
\text { vs. Emapalumab }\end{array}$ & NCT04324021 & $\|/\| \|$ & Italy (4) & 54 & Pneumatic COVID19+ & $\begin{array}{l}\text { Anakinra (IL1r antagonist); } \\
\text { Emapalumab (anti-IFN } \gamma \text { ) }\end{array}$ \\
\hline & Anakinra \pm Ruxolitinib & NCT04366232 & $\|$ & France (3) & 54 & Severe COVID19+ & \\
\hline Anti-GM-CSF & Mavrilimumab & NCT04337216 & $\|$ & Virginia, USA & 10 & Pneumatic COVID19+ & $\begin{array}{l}\text { GM-CSF is one of the main mediators } \\
\text { of CRS in severe COVID19 patients }\end{array}$ \\
\hline \multirow[t]{2}{*}{ Jak Inhibitor } & Baricitinib & NCT04399798 & $\|$ & Pavia, Italy & 13 & Pneumatic COVID19+ & $\begin{array}{l}\text { Inhibits JAK1-/JAK2-mediated } \\
\text { cytokine release and TNF-alpha }\end{array}$ \\
\hline & Ritonavir \pm Baricitinib & NCT04320277 & III & Tuscany, Italy & 60 & $\begin{array}{l}\text { Moderate/pneumonia } \\
\text { COVID19+ }\end{array}$ & \\
\hline $\begin{array}{l}\text { Extracorporeal } \\
\text { adsorption }\end{array}$ & CytoSorb absorber & NCT04324528 & N/A & $\begin{array}{l}\text { Freiburg, } \\
\text { Germany }\end{array}$ & 30 & Pneumatic COVID19+ & $\begin{array}{l}\text { "Absorbs" IL-6 in effort to reduce } \\
\text { inflammation in ARDS patients }\end{array}$ \\
\hline \multicolumn{8}{|c|}{ Anti-inflammatories } \\
\hline \multirow[t]{4}{*}{ Corticosteroid } & $\begin{array}{l}\text { Ciclesonide } \\
\pm \text { Hydroxychloroquine }\end{array}$ & NCT04330586 & $\|$ & Seoul, Korea & 141 & $\begin{array}{l}\text { Early COVID19+ (within } 7 \\
\text { days) }\end{array}$ & $\begin{array}{l}\text { Ciclesonide is an } \\
\text { anti-inflammatory corticosteroid }\end{array}$ \\
\hline & Prednisone & NCT04344288 & $\|$ & Bron, France & 304 & Pneumatic COVID19+ & $\begin{array}{l}\text { Prednisone is an } \\
\text { anti-inflammatory corticosteroid }\end{array}$ \\
\hline & Hydrocortisone & NCT04348305 & III & Denmark & 1000 & Pneumatic COVID19+ & Low-dose hydrocortisone for 7 days \\
\hline & Dexamethasone & NCT04344730 & N/A & Paris, France & 550 & $\begin{array}{l}\text { COVID19+ ICU within } \\
\text { 48hrs }\end{array}$ & $\begin{array}{l}\text { Dexamethasone is an } \\
\text { anti-inflammatory corticosteroid }\end{array}$ \\
\hline
\end{tabular}


TABLE 2 | Continued

\begin{tabular}{|c|c|c|c|c|c|c|c|}
\hline Category & Therapeutic(s) & Trial identifier & Phase & $\begin{array}{l}\text { Location } \\
\text { (centers) }\end{array}$ & Patients (n) & Study eligibility & Mechanism of action(s) \\
\hline & Dexamethasone & NCT04325061 & IV & Spain (24) & 200 & $\begin{array}{l}\text { Severe COVID19+ on } \\
\text { ventilator }\end{array}$ & \\
\hline & Dexamethasone & NCT04327401 & III & Brazil (21) & 290 & ARDS patients & \\
\hline & Methylprednisolone & NCT04343729 & $\|$ & Brazil & 420 & Pneumatic COVID19+ & $\begin{array}{l}\text { Methylprednisolone is an } \\
\text { anti-inflammatory corticosteroid }\end{array}$ \\
\hline & $\begin{array}{l}\text { Methylprednisolone } \\
\text { (vs. Tocilizumab) }\end{array}$ & NCT04345445 & III & $\begin{array}{l}\text { Kuala Lumpur, } \\
\text { Malaysia }\end{array}$ & 310 & $\begin{array}{l}\text { COVID19+ with high risk } \\
\text { of CRS }\end{array}$ & \\
\hline & $\begin{array}{l}\text { Methylprednisolone } \\
\text { (vs. Siltuximab) }\end{array}$ & NCT04329650 & $\|$ & $\begin{array}{l}\text { Barcelona, } \\
\text { Spain }\end{array}$ & 200 & Pneumatic COVID19+ & \\
\hline \multirow[t]{2}{*}{ NSAID } & Naproxen & NCT04325633 & III & Paris, France & 584 & Pneumatic COVID19+ & COX-2 inhibitor \\
\hline & Ibuprofen & NCT04334629 & IV & Not listed & 230 & $\begin{array}{l}\text { NEWS2 > } 5 \text { overall, } \\
\text { Pneumatic }\end{array}$ & \\
\hline
\end{tabular}

NEWS, National Early Warning Score; HCW, Healthcare Workers; As of June 1, 2020.

trials, the promising safety profile of CAR-NK cells in cancer patients, who are often immunocompromised, suggests that CAR-NK therapy can be well-tolerated in early phase/mild COVID-19 patients. Notably, CAR-NK cells are considered "safe" largely because they are less likely to lead to cytokine release syndrome (CRS), a severe adverse event of CAR-T cell therapy (165). But as these are unchartered waters, it is critical that CAR-NK cells are used cautiously and not given to late/severe COVID-19 patients.

A Phase I/II study in early stage COVID-19 patients (within 14 days of illness) employing CAR-NK cell therapy is currently being tested using off-the-shelf NK cells derived from human umbilical cord blood expressing NKG2D and ACE2 CARs (NCT04324996). This complex five-arm study will compare the efficacy of different CAR-NK constructs: (i) NK cells, (ii) NK cells secreting IL-15, (iii) NKG2D CAR-NK cells, (iv) ACE2 CAR-NK cells, and (v) NKG2D-ACE2 CAR-NK cells. NKG2D CAR-NK cells have shown promising preclinical results in cancer studies (166), and although not proven for SARS-CoV-2, the rationale for expressing NKG2D derives from work showing that NKG2D-ligands (NKG2DL) are upregulated on virally infected cells (167). Similarly, the investigators hypothesize that expressing ACE2 on NK cells will facilitate the elimination of SARS-CoV-2 virions and infected cells by binding the viral spike proteins-but it is unknown whether or not CAR-NK cells can eliminate virions or if infected cells display sufficient levels of spike protein to be recognized by ACE2-NK cells upon viral infection. The investigators also suggest that expressing ACE2 on NK cells may also have a secondary benefit as a decoy cell that will be infected by the virus thereby indirectly protecting lung epithelial cells. As described previously, it is unclear whether this strategy will work to stop viral spread to healthy epithelial cells or if it will serve to perpetuate viral spread if the virus can replicate in NK cells. In arms ii-v of this trial, the CAR-NK cells have been engineered to secrete IL15 based on studies showing improved in vivo persistence of CAR-NK cells in cancer patients (168). However, the addition of the proinflammatory cytokine IL-15 to this treatment strategy should be monitored closely for life-threatening toxicities, as elevated IL-15 has been previously reported to accompany chronic pulmonary inflammatory diseases (169) and MERS-CoV infection (170) even if no correlation has been reported for SARSCoV-2. Interestingly, a study compared IL-15 levels from lung tissue homogenates following SARS-CoV infection in aged vs. juvenile monkeys and showed that IL-15 concentrations were only elevated in juvenile monkeys 10 days post-infection (171). This study would suggest that IL-15 therapy may be tolerated and effective in older COVID-19 patients that may not be able to produce IL-15, however this has not been confirmed. Lastly, all the CAR-NK cells in this trial secrete GM-CSF neutralizing scFv antibodies, since this cytokine has a known role in CRS in cancer patients treated with CAR-T cells (172), and has been shown to be correlated with COVID-19 disease severity in association with pathogenic $\mathrm{CD} 4^{+}$Th1 cells (173).

Although NK cell based therapies are versatile, have shown safety and efficacy in cancer patients, and can be utilized in immunocompromised individuals, their potential has yet to be fully realized as an antiviral therapy. Furthermore, the logistics of manufacturing NK cell products (cost and time) may pose limitations and barriers to access. For this reason, therapies focused on stimulating a patient's own NK cells offer many advantages over adoptive transfer of NK cells.

\section{Interferon Therapy and NK Cells}

The importance of the interferon pathway is underscored by the fact that many viruses actively interfere with host interferon responses, for which coronaviruses are a prime example. As described above, CoVs utilize numerous tactics to avoid elimination by disrupting the host type I IFN response (174). Therefore, since the majority of CoVs fail to induce any detectable type I IFN response, eliciting a type I IFN response is a very attractive therapeutic strategy $(118,175)$.

Given the robust immunomodulatory nature of type I IFNs, uninfected or early symptomatic patients would benefit the most from this therapy to prevent exacerbating immunopathology at 
later stages of disease. Numerous clinical trials have been initiated investigating type I IFNs (Table 1). A large study (NCT04320238) of $\sim 3,000$ medical staff allocated participants to two trial arms: (i) low-risk (non-isolated wards or laboratories) or (ii) highrisk (isolated wards in direct contact with COVID-19 patients). In addition to the IFN- $\alpha-1 b$ nasal drops, high-risk medical staff will also receive the immune-modulating TLR activator, thymosin $\alpha 1$, which indirectly activates NK cells through pDCs $(176,177)$. Interestingly, reports in SARS-CoV-1 studies showed that IFN- $\beta$ therapy had a 50 -fold greater anti-viral activity in Vero cells than IFN- $\alpha$ treatment (178). Promising results have been published from a Phase II study (NCT04276688) (179), showing that complementing lopinavir-ritonavir and ribavirin with subcutaneous IFN- $\beta$-1b in mild-to-moderate COVID-19 patients is safe with no serious adverse events reported in the triple combination therapy group, and highly effective, with significant and clinically meaningful reductions in time to complete alleviation of symptoms, hospital length of stay, and time to negative viral load (179).

Despite our best efforts in timing type I IFN therapy to mitigate immunopathology, these treatments still increase the risk of excessive activation of proinflammatory signals, which could damage host tissues and perpetuate immunopathology $(180,181)$. For this reason, alternative therapeutic avenues to direct type I IFN administration are being explored.

Type III IFNs can be a valid alternative to type I IFNs, because they maintain antiviral functions yet are less toxic and less prone to mediate immunopathology (182). The type III IFN, IFN- $\lambda$, activates NK cells indirectly (compared to type I IFNs which directly act on NK cells), resulting in a less potent and slower immune response $(183,184)$. IFN- $\lambda$ activates NK cells by stimulating macrophages to produce IL-12 which in turn induce NK cells to produce IFN- $\gamma$ (185). Pegylated IFN$\lambda$ is being tested in COVID-19 positive patients with mild symptoms in the absence of respiratory distress (NCT04331899). While IFN- $\lambda$ can lead to the eventual activation of NK cells, its primary utility is in preventing the tissue damaging potential of neutrophils at mucosal surfaces, such as the lungs. However, IFN $-\lambda$ also has been shown to reduce the rate of tissue repair, which in the context of COVID-19 which has a long disease course, could mean greater risk of secondary infections. Since exogenous administration of any IFN therapy poses the risk of tipping the balance toward severe COVID-19 immunopathology, Broggi et al. assessed the levels of IFNs in upper and lower respiratory samples from healthy and COVID-19 patients. In this preprint, they report that while the upper airway swabs showed similar mRNA expression levels of type I and III IFN compared to healthy controls, the BALF samples of severe COVID-19 patients had significantly elevated type I and III IFN levels (186). Therefore, as with all of the therapies discussed in this review, careful consideration about safe and effective timing should guide our design of clinical trials.

\section{Interleukin Therapy and NK Cells}

In addition to IFN cytokine therapy, interleukin cytokine therapy can enhance the effector functions of NK cells (158). The use of whole, unmodified recombinant cytokines as a monotherapy has resulted in minimal success in humans in cancer immunotherapy. The earliest cytokine therapies to gain FDA-approval were IFN- $\alpha$ and recombinant IL-2, approved for renal cell carcinoma and metastatic melanoma (187). Although approved, they were limited by their in vivo half-life, marginal anti-tumor activity, and associated toxicities. The next generation of cytokine therapies were created to address these issues by first improving their biological stability through pegylation and fusion to chaperone molecules and secondly improving their specificity by fusing cytokines with antibodies or intratumoral administration. These advances in the field have allowed for the reassessment of the therapeutic potential of specific cytokines (187).

Given the importance of IL-15 signaling and NK cell function, researchers have developed IL-15 "superagonists" which are IL15:IL-15R heterodimers that have better in vivo stability and bioactivity compared to monomeric IL-15 (168). Although at the time of writing IL-15 superagonists are not being studied for their efficacy in COVID-19 patients, IL-15 superagonists, such as ALT-803, are safe in humans (188) and have been used in conjunction with many of the therapies being discussed in this review including: CAR-NK cell therapy, adoptive NK cell transfers, checkpoint inhibitors, and the BCG vaccine in cancer (189). It should be noted that although the therapeutic potential of cytokine therapy to specifically stimulate NK cells is enticing, exogenous cytokine therapy has a high risk for exacerbating CRS if given at the incorrect time.

\section{Checkpoint Immunotherapies and NK Cells}

Some viruses are known to induce a state of functional hyporesponsiveness in $\mathrm{T}$ cells that is essential for the productive establishment of chronic viral infections (190). A vast body of literature has identified inhibitory checkpoint receptors, including CTLA4 and PD-1, as key regulators of this process (191). Interestingly, cancer exploits similar mechanisms to escape the immune response, which provided the rationale for the introduction of antibodies targeting checkpoint receptors for cancer immunotherapy (192). CTLA4 and PD-1/PD-L1 blockade have revolutionized cancer immunotherapy, and their success provides a strong rationale for the use of these drugs in COVID19 patients, where emerging evidence suggests that the immune response is also subverted. A clinical trial (NCT04268537) is currently assessing the efficacy of PD-1 blocking antibodies in severe COVID-19 patients within $48 \mathrm{~h}$ of reported respiratory distress. PD-1 has also been shown to play a role in regulating NK cell responses, in addition to modulating $\mathrm{T}$ cell functions (193-197), and has been reportedly increased in COVID-19 patients (129).

Inhibitory receptors on the surface of NK cells regulate NK cell activation and can be targeted by antibody therapy. One of the most promising is certainly the inhibitory receptor NKG2A, which binds to HLA-E (74, 198, 199). NKG2A expression is increased in circulating (127) and BALF NK cells from COVID19 patients, in contrast to NKG2C, an activating receptor closely related to NKG2A, which remains unchanged (129). However, it is unclear whether the observed increase in $\mathrm{NKG}_{2} \mathrm{~A}^{+} \mathrm{NK}$ cells is due selective proliferation of $\mathrm{NKG}_{2} \mathrm{~A}^{+}$cells or if it is the result 
of NKG2A negative cells migrating out of circulation to infected tissues. Circulating NK cells from patients with active hepatitis B disease had higher levels of NKG2A compared to patients without active disease, however antiviral administration was associated with a reduction in NKG2A expression. Additionally, blocking NKG2A in vitro with NKG2A monoclonal antibodies led to improved NK cytotoxicity (200). Given the association between NKG2A expression in patients with severe COVID-19 $(127,201)$, a promising avenue of investigation would be antiNKG2A therapy, even in light of results showing that NKG2A ${ }^{+}$ NK cells are tuned to present a higher level of responsiveness to stimulation (202).

\section{INDIRECT NK CELL ACTIVATION THROUGH INNATE IMMUNE STIMULATION}

While NK cells can be stimulated directly by cytokines such as interferons and interleukins, their activity can also be enhanced through a by-stander effect following stimulation of other innate immune cells, such as macrophages and pDCs (Table 1). This type of coordinated innate immune response may be more effective at $\mathrm{CoV}$ viral clearance and mitigation of severe COVID-19.

\section{Trained Immunity and Heterologous Vaccines}

Trained immunity has been recently described as an epigenetic re-wiring occurring in myeloid cells and progenitors upon stimulation that primes for a stronger response to subsequent stimuli, even of a different nature $(90,203,204)$. Whereas, the consensus is that myeloid cells are primarily responsible for trained immunity (205), it is likely that the resulting alteration in the cytokine milieu also has an effect on NK cells $(204,206)$. This is the case for the BCG vaccine, which has been shown to provide non-specific protection against yellow fever viral infection (90, 207, 208). The BCG vaccine is composed of a live attenuated strain of Mycobacterium bovis originally given to young children to protect against tuberculosis (M. tuberculosis) (209). This vaccine provides an initial boost to innate immunity, but more importantly, results in the secretion of IL- $1 \beta$ from monocytes/macrophages, which feeds back to further stimulate the innate response (204).

The use of a heterologous vaccine to provide enhanced protection against non-specific/new pathogens makes this a compelling strategy against COVID-19 that warrants thorough investigation in randomized controlled trials $(209,210)$. The BCG vaccine is undergoing clinical trials in healthcare workers in the Netherlands (NCT04328441), Australia (NCT04327206), Egypt (NCT04350931), and the USA (NCT04348370) to enhance overall innate immunity and provide heterologous protection against SARS-CoV-2. Interestingly, an association was found that linked lower COVID-19-attributable mortality rates in countries using BCG in their national immunization schedules (211). On the contrary, a study that assessed the association of childhood BCG vaccination in adults living in Israel did not show a beneficial difference in COVID-19 infection rates. The discrepancy between these two reports likely stem from the fact that the latter study only included adults who were previously vaccinated during childhood, supporting the fact that heterologous vaccination may not result in long-term protection (212). Childhood BCG immunization has a limited window of opportunity to protect younger individuals from infection (213), but it is hypothesized that reducing the number of infected children can have a meaningful impact on curbing the spread of COVID-19 to the rest of the population $(206,211)$. Another heterologous vaccine in the process of clinical trial development for COVID-19 studies is IMM-101 (CCTG ID\# IC8). Created by Immodulon Therapeutics LTD, IMM-101 is composed of heatkilled Mycobacterium obuense and may have an improved safety profile over the BCG vaccine (214). IMM-101 has been studied in multiple clinical trials for its non-specific immune stimulating properties as a cancer immunotherapy in pancreatic (215) and melanoma patients $(216,217)$.

\section{Toll-like Receptor Agonist Therapy}

Agonists of Toll-Like Receptors (TLRs) have been shown to broadly activate different immune populations and have had both preclinical and clinical success as adjuvants in vaccination and in the treatment of a variety of viral pathogens (218). For example, CpG oligodeoxynucleotides (CpG ODNs) are short DNA sequences that contain unmethylated $\mathrm{CpG}$ dinucleotides which activate TLR9 particularly on DCs and B cells (219). Bao et al. showed that their CpG ODN construct, BW001, had protective effects against SARS-CoV-1 in a mechanism that relied on NK cell activation likely through a DC intermediate (220). Amidst the ongoing SARS-CoV-2 pandemic, two clinical trials (NCT04313023, NCT04312997) have opened using the TLR2/6/9 agonist, PUL-042, in order to prevent infection.

\section{Immune-Boosting Natural Health Products}

Ascorbic acid, more commonly known as vitamin $\mathrm{C}$, has been shown to exhibit potent immunomodulatory, antioxidant, and antimicrobial effects (221). Vitamin C has been shown to restore NK cell cytotoxicity in individuals exposed to toxic chemicals through protein kinase $\mathrm{C}$ expression, a critical component in lymphocyte metabolism (222). Additional reports have shown that vitamin C also enhances the expression of NKp46, CD69, CD25 and IFN- $\gamma$ production by NK cells (223) and can increase the expression of IRF3 in lung tissues of influenza infected, pneumonia-induced mice (224). Vitamin C also harbors potent antioxidant attributes which can scavenge reactive oxygen species (ROS) and prevent lung injury $(225,226)$. Although ROS production is an important component in the host defense response to viruses, they can be harmful to cells and lead to the pathogenesis of viral-induced host injury (227).

The underlying rationale to investigate the therapeutic potential of vitamin $\mathrm{C}$ has been based on two key observations: (i) critically ill patients have lower levels of vitamin C (228-230) and (ii) vitamin $\mathrm{C}$ has pleiotropic immunomodulatory, antioxidant, and antiviral effects (221). It is important to underscore that reports on the clinical outcomes of vitamin $\mathrm{C}$ treatment in 
humans are mixed and context dependent. A thorough metaanalysis on vitamin $\mathrm{C}$ supplementation for the common cold has been reported by Hemilä and Chalker (231). Briefly, they concluded that while the incidence of colds was not reduced, the duration and severity of colds was reduced when assessing studies of regular vitamin C intake (231). Interestingly, a separate metaanalysis on vitamin $C$ and cardiac surgery showed a reduction in the length of ICU stay and shortened the need for mechanical ventilation (232). This is an important correlation as clinical trials are currently investigating the efficacy of vitamin $C$ to reduce mortality and hospital burden in COVID-19 patients (Table 1). A Phase II clinical trial (NCT04264533) was initiated in Wuhan where COVID-19 patients will be given a high dose intravenous infusion of vitamin C. Lastly, whether oral dosing of vitamin C can achieve therapeutically relevant concentrations, as described in the above studies, is currently unknown, thus caution should be taken as exceeding the recommended dietary allowance of $100-200 \mathrm{mg} /$ day may lead to mild toxicities including abdominal discomfort and diarrhea $(231,233)$.

\section{MITIGATING IMMUNOPATHOLOGY IN SEVERE COVID-19 PATIENTS}

The main cause of death for COVID-19 patients has been pulmonary complications and respiratory failure often as a result of an unregulated cytokine storm (234). It is unclear whether the hyperinflammation seen in severe cases of COVID19 is the result of the viral replication within pulmonary epithelial cells or an overactive/avalanching immune response. However, studies in SARS-CoV-1 reported hyperinflammation in later stages of disease progression, despite reduced viral titers, suggesting that the damage was immune-mediated (19). The most appropriate course of therapy can only be determined by elucidating the pathophysiology of disease progression. Scientists and physicians, however, have had to respond quickly to the growing number of severe COVID-19 cases and this has resulted in therapy mainly through a combination of anti-inflammatory and anti-viral interventions (Table 2). As described above, there is a potential for NK cells to contribute to the cytokine storm and therefore the development of ALI. A possible explanation for the observed lymphopenia in COVID-19 patients is that NK cells and other lymphocytes migrate out of the circulation and into pulmonary tissues to aid in the elimination of infected epithelial cells (235). This could be the premise for the large, unintended, amount of tissue damage that worsen the respiratory distress (148). For this reason, therapeutics that dampen the immune response have been effective in mitigating immunopathology in severe COVID-19 patients. The following review papers have thoroughly discussed many of these immunotherapies already (236-241), therefore, this section will focus on immunotherapies and their potential implications on NK cells.

\section{Anti-cytokine Therapy}

The main cytokines responsible for the life threatening respiratory distress seen in reported cases of severe COVID19 are IL-2, IL-6, IL-7, IL-10, G-CSF, IP-10, MCP-1, MIP1A, and TNF- $\alpha$ (234). Many clinical trials have focused on targeting IL-6 signaling with anti-IL-6R monoclonal antibodies (e.g., tocilizumab, sarilumab, siltuximab) because of the important role IL-6 has in propagating CRS (242). Tocilizumab, in particular, is being used as the primary therapy in the majority of these trials, likely owing to its FDA approved status as a therapeutic for CRS in CAR-T cell therapy (243). A case report demonstrated the potential for tocilizumab therapy in treating severe COVID19 illness, where a single dose on day 24 of symptoms led to progressive reduction in IL-6 levels and resolution of symptoms (244). A Phase III study (NCT04320615) led by Hoffman-La Roche is recruiting patients to study the safety and efficacy of tocilizumab therapy in a randomized, double-blind, placebocontrolled, multicenter study in over 300 patients with severe COVID-19 pneumonia (Table 2). Targeting the IL-6 axis in severe COVID-19 patients may also serve to improve NK cell functions as Cifaldi et al. showed that increased IL-6 negatively impacts NK cell function (245). They also showed that tocilizumab treatment improved NK cell function in vitro (245). Mazzoni et al. recently reported that serum IL-6 levels were inversely correlated $(p=0.01)$ with NK cell function in COVID19 ICU patients. Additionally, in a small subset of COVID-19 ICU patients $(n=5)$, NK cells displayed improved markers of activation (granzyme A and perforin) after tocilizumab treatment (246).

Similar therapies have emerged in the fight against COVID19 including an IL-1R antagonist (Anakinra; NCT04330638) (247) and Cytosorb (NCT04324528) (248). High dose anakinra therapy has shown promising safety and efficacy in a small retrospective study, as part of the COVID-19 Biobank study (NCT04318366) (247). Cytosorb therapy is used in conjunction with conventional dialysis through a whole blood cartridgebased filtration system designed to remove middle molecular weight molecules (which include inflammatory cytokines $<75$ $\mathrm{kDa}$ ) through extracorporeal cytokine adsorption (248). It is reported to be effective at removing Ferritin and IL-6 in a case study of a 14-year-old with severe CRS following CAR-T cell therapy (249).

Jak1/2 inhibitors (JAKi) are also undergoing clinical trials in moderate-severe COVID-19 patients, such as baricitinib (NCT04320277). In addition to their ability to impede the production of IL-6, thus curb the excessive inflammation, they may also block clathrin mediated endocytosis-indicating a dual role for JAKi (241). However, JAKi can also lead to the transient increase in NK cells as shown in baricitinib treated Rheumatoid Arthritis patients (250), which could be detrimental for severe COVID-19 patients.

\section{Corticosteroids}

Corticosteroids have played a key role in the treatment of auto-immune diseases over the past 70 years $(251,252)$. Whether endogenous or exogenous, corticosteroids decrease the number of circulating monocytes and lymphocytes and decrease synthesis of pro-inflammatory cytokines (IL-2, IL-6, TNF- $\alpha$ ) (251). Their strong anti-inflammatory and immunosuppressive effects make them good candidates for rapidly suppressing inflammation during early auto-immune disease or viral 
infections. Corticosteroids have been shown to inhibit NK cells in ex vivo experiments $(253,254)$. While corticosteroids may delay clearance of infections, their major benefit lies in suppressing excessive innate immune responses, thus preventing lung damage and ARDS commonly present in severe viral infections (255-257). In fact, this was the main rationale for the widespread use of corticosteroids during MERS and SARS infections $(255,256)$. Specific to COVID-19, some groups have advocated for the use of low-dose corticosteroids in a specific subset of critically-ill patients with refractory ARDS, sepsis, or septic shock (Table 2) (257). There is one known ongoing randomized clinical trial examining the effect of the corticosteroid ciclesonide in adults with mild COVID-19 infections (NCT04330586). This trial is based on preclinical studies showing in vitro antiviral activity of ciclesonide against SARS-CoV-2.
While there may be a benefit to using corticosteroids in a subset of critically-ill patients with refractory ARDS or sepsis (257), their routine use in COVID-19 is not recommended outside of clinical trials, based on expert opinion and WHO recommendations (258-260). Corticosteroids also cause a multitude of side effects, most notably diabetes mellitus, osteoporosis, and increased risk of infections (251). Controversially, a 2019 systematic review of over 6,500 influenza patients showed that corticosteroids actually led to increased mortality, length of ICU stay, and secondary infections (261). Additionally, one retrospective observational study examined the use of corticosteroids in 31 COVID-19 patients, and reported no significant association between corticosteroids and viral clearance time, hospital length of stay, or duration of symptoms (262). These studies highlight the need to be vigilant in our attempts to fight COVID-19.

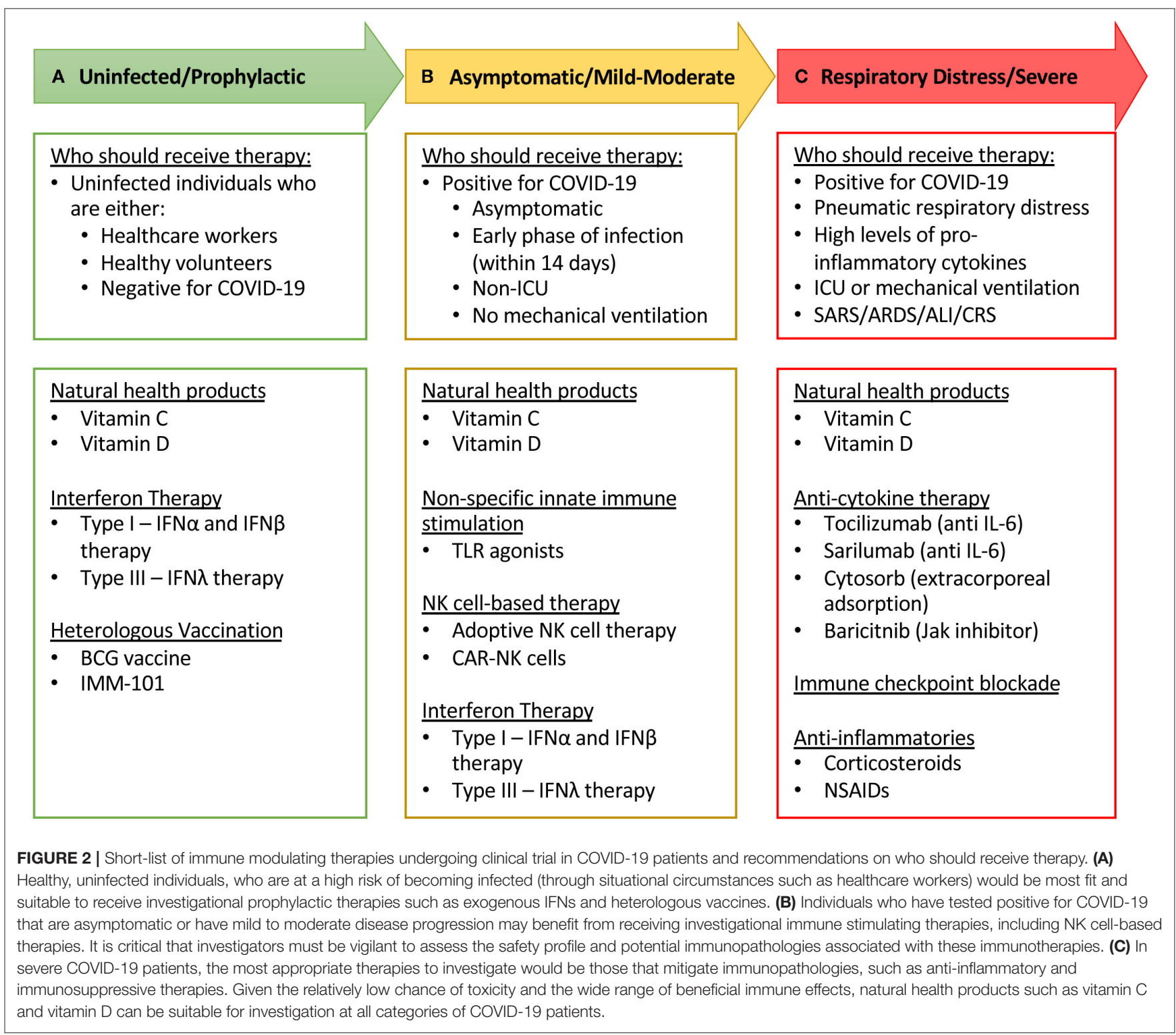




\section{Non-steroidal Anti-inflammatory Drugs (NSAIDs)}

Non-steroidal anti-inflammatory drugs, or NSAIDs, are one of the most commonly prescribed drugs for treating fever, pain, and inflammation. NSAIDs include over-the-counter household names such as ibuprofen, naproxen, and aspirin. Given the widespread use of these medications it is appropriate that researchers have investigated the potential benefits and harms of NSAIDs in patients diagnosed with COVID-19. Thus far, the evidence for using NSAIDs in the context of CoVs are mixed and might not be generalizable to all NSAIDs as reports tended to focus on specific NSAIDs. These studies also focused on the potential for NSAIDs to act as an antiviral, with a potential added benefit of being able to treat inflammatory symptoms. One report showed that the NSAID indomethacin could directly inhibit SARS-CoV replication in Vero cell monolayers in a dosedependent manner (263). The antiviral properties of naproxen have been described in the context of influenza virus $(264,265)$ and has prompted the initiation of a clinical trial investigating the efficacy of naproxen as a treatment for critically ill COVID-19 infected patients (NCT04325633).

NSAID therapy should be used with caution as they have been shown to interfere with immune responses and ability to produce antibodies, with ibuprofen having the greatest suppressive effect (266). Furthermore, ibuprofen has been reported to increase the expression of the ACE2 receptor (267) which could facilitate SARS-CoV-2 viral entry. This finding should be considered for any current (NCT04334629) and potential COVID-19 clinical trial assessing ibuprofen therapy. NSAIDs also have been shown to have a direct suppressive effect on NK cell IFN- $\gamma$ and TNF- $\alpha$ production (268) which may be beneficial for late stage COVID19 patients.

\section{CONCLUSIONS AND FURTHER STUDY}

The relevance of NK cells as antiviral first responders is highlighted in patients with NKD and immunocompromised individuals who show increased susceptibility to viral infections. While there is currently little direct evidence to support a role for NK cells in the clearance of SARS-CoV-2 there is a paucity of research in this field. However, studies in admitted COVID-19 patients with mild and severe disease reported a reduction in circulating NK cell levels and function as compared to healthy individuals. Furthermore, reduced NK cell levels and function were inversely correlated with disease severity, suggesting that NK cells may be involved in some capacity. One of the potential mechanisms by which NK cells may become hyporesponsive is via SARS-CoV-2 interference with type I IFN pathways. In investigating the pathogenesis of other $\mathrm{CoV}$ infections, namely SARS and MERS, studies suggest that during

\section{REFERENCES}

1. Lodoen MB, Lanier LL. Natural killer cells as an initial defense against pathogens. Curr Opin Immunol. (2006) 18:391-8. doi: 10.1016/j.coi.2006.05.002 acute $\mathrm{CoV}$ infection, inflammatory monocyte-macrophages and neutrophils accumulate in the lungs and produce chemokines and cytokines that induce NK cell migration and activation. As NK cells are one of the main producers of IFN- $\gamma$, they may be involved in the IFN- $\gamma$-led cytokine storm that is responsible for the induction of inflammation-mediated ALI, ARDS, and subsequent mortality associated with COVID-19. Inarguably, more research into the role of NK cells in COVID-19 is required. Despite the knowledge gaps in COVID-19 pathophysiology, there has been a surge of clinical trials as the FDA continues to fast-track the approval of investigational therapeutics (269). Here we have outlined potential therapeutics with a focus on mediating NK cell activity, including prophylactic treatments that could boost innate immunity in addition to therapeutics that could mitigate the immunopathological consequences of COVID-19, thereby relieving the burden on our health care systems (Figure 2). Rigorous preclinical testing and thoughtfully designed clinical trials will be necessary for the development of robust therapeutics against SARS-CoV-2. Importantly, we must be aware of the potential dangers immunotherapies may have in potentiating $\mathrm{CoV}$ immunopathology. The fight against COVID19 is not an easy one. As with any novel disease, we will have to rely on incomplete pictures to guide reasoning for appropriate treatment. We believe that immunotherapeutics targeting the innate immune response, and specifically NK cells, have the potential to flatten the curve and will be important instruments in our armamentarium against this pandemic and the next.

\section{AUTHOR CONTRIBUTIONS}

MM, LA, AM, DB, OO, GT, DMB, and JN contributed to literature review. MM, LA, AM, DB, OO, and GT contributed to writing. MM, LA, MA, and RA were responsible for editing. MM and LA were responsible for formatting. MA and RA oversaw the writing process and provided mentorship and guidance. All authors contributed to the article and approved the submitted version.

\section{FUNDING}

The authors have received funding from the Canadian Institutes of Health Research, the Cancer Research Society, and the Ontario Student Assistance Program through a Queen Elizabeth II Graduate Scholarship in Science and Technology. The Ottawa Hospital Academic Medical Organization and The Ottawa Hospital Foundation.

\section{ACKNOWLEDGMENTS}

The authors would like to thank Dr. Doug Gray for his thorough editing, proofreading, and thoughtful suggestions.

2. Brandstadter JD, Yang Y. Natural killer cell responses to viral infection. $J$ Innate Immun. (2011) 3:274-9. doi: 10.1159/000324176

3. Jost S, Altfeld M. Control of human viral infections by natural killer cells. Annu Rev Immunol. (2013) 31:163-94. doi: 10.1146/annurev-immunol-032712-100001 
4. Li F, Zhu H, Sun R, Wei H, Tian Z. Natural killer cells are involved in acute lung immune injury caused by respiratory syncytial virus infection. $J$ Virol. (2012) 86:2251-8. doi: 10.1128/JVI.06209-11

5. Abdul-Careem MF, Mian MF, Yue G, Gillgrass A, Chenoweth MJ, Barra NG, et al. Critical role of natural killer cells in lung immunopathology during influenza infection in mice. J Infect Dis. (2012) 206:167-77. doi: 10.1093/infdis/jis340

6. Zhou G, Juang SWW, Kane KP. NK cells exacerbate the pathology of influenza virus infection in mice. Eur J Immunol. (2013) 43:929-38. doi: 10.1002/eji.201242620

7. McKinstry KK, Alam F, Flores-Malavet V, Nagy MZ, Sell S, Cooper AM, et al. Memory CD4 T cell-derived IL-2 synergizes with viral infection to exacerbate lung inflammation. PLoS Pathog. (2019) 15:e1007989. doi: 10.1371/journal.ppat.1007989

8. Scharenberg M, Vangeti S, Kekäläinen E, Bergman P, Al-Ameri M, Johansson $\mathrm{N}$, et al. Influenza A virus infection induces hyperresponsiveness in human lung tissue-resident and peripheral blood NK cells. Front Immunol. (2019) 10:1116. doi: 10.3389/fimmu.2019.01116

9. Ghosh S, Nandi M, Pal S, Mukhopadhyay D, Chakraborty BC, Khatun $\mathrm{M}$, et al. Natural killer cells contribute to hepatic injury and help in viral persistence during progression of hepatitis $\mathrm{B}$ e-antigen-negative chronic hepatitis B virus infection. Clin Microbiol Infect. (2016) 22:733.e9-733.e19. doi: 10.1016/j.cmi.2016.05.009

10. Waggoner SN, Cornberg M, Selin LK, Welsh RM. Natural killer cells act as rheostats modulating antiviral T cells. Nature. (2011) 481:394-8. doi: $10.1038 /$ nature 10624

11. Zhu N, Zhang D, Wang W, Li X, Yang B, Song J, et al. A novel coronavirus from patients with pneumonia in China, 2019. N Engl J Med. (2020) 382:72733. doi: 10.1056/NEJMoa2001017

12. Lie SA, Wong SW, Wong LT, Wong TGL, Chong SY. Practical considerations for performing regional anesthesia: lessons learned from the COVID-19 pandemic. Can J Anaesth. (2020) doi: 10.1007/s12630-020-01637-0

13. Weiss SR, Navas-Martin S. Coronavirus pathogenesis and the emerging pathogen severe acute respiratory syndrome coronavirus. Microbiol Mol Biol Rev. (2005) 69:635-64. doi: 10.1128/MMBR.69.4.635-664.2005

14. Su S, Wong G, Shi W, Liu J, Lai ACK, Zhou J, et al. Epidemiology, genetic recombination, and pathogenesis of coronaviruses. Trends Microbiol. (2016) 24:490-502. doi: 10.1016/j.tim.2016.03.003

15. Ashour HM, Elkhatib WF, Rahman MM, Elshabrawy HA. Insights into the recent 2019 novel coronavirus (SARS-CoV-2) in light of past human coronavirus outbreaks. Pathogens. (2020) 9:186. doi: $10.3390 /$ pathogens 9030186

16. Bradburne AF, Bynoe ML, Tyrrell DA. Effects of a "new" human respiratory virus in volunteers. Br Med J. (1967) 3:767-9. doi: 10.1136/bmj.3.5568.767

17. Hamre D, Procknow JJ. A new virus isolated from the human respiratory tract. Proc Soc Exp Biol Med. (1966) 121:190-3. doi: 10.3181/00379727-121-30734

18. Mesel-Lemoine M, Millet J, Vidalain P-O, Law H, Vabret A, Lorin V, et al. A human coronavirus responsible for the common cold massively kills dendritic cells but not monocytes. J Virol. (2012) 86:7577-87. doi: 10.1128/JVI.00269-12

19. Channappanavar R, Perlman S. Pathogenic human coronavirus infections: causes and consequences of cytokine storm and immunopathology. Semin Immunopathol. (2017) 39:529-39. doi: 10.1007/s00281-017-0629-x

20. World Health Organization. Consensus document on the epidemiology of severe acute respiratory syndrome (SARS). World Health Organization (2003). Available online at: https://apps.who.int/iris/handle/10665/70863 (accessed April 5, 2020).

21. WHO. Middle East respiratory syndrome coronavirus (MERS-CoV). (2020) Available online at: http://www.who.int/emergencies/mers-cov/en/ (accessed April 5, 2020).

22. Boileau MJ, Kapil S. Bovine coronavirus associated syndromes. Vet Clin North Am Food Anim Pract. (2010) 26:123-46. doi: 10.1016/j.cvfa.2009.10.003

23. Felten S, Hartmann K. Diagnosis of feline infectious peritonitis: a review of the current literature. Viruses. (2019) 11:1608. doi: 10.3390/v11111068

24. Cui J, Li F, Shi Z-L. Origin and evolution of pathogenic coronaviruses. Nat Rev Microbiol. (2019) 17:181-92. doi: 10.1038/s41579-018-0118-9
25. Li F. Structure, function, and evolution of coronavirus spike proteins. Annu Rev Virol. (2016) 3:237-61. doi: 10.1146/annurev-virology-110615-042301

26. Li W, Zhang C, Sui J, Kuhn JH, Moore MJ, Luo S, et al. Receptor and viral determinants of SARS-coronavirus adaptation to human ACE2. EMBO J. (2005) 24:1634-43. doi: 10.1038/sj.emboj.7600640

27. Raj VS, Mou H, Smits SL, Dekkers DHW, Müller MA, Dijkman R, et al. Dipeptidyl peptidase 4 is a functional receptor for the emerging human coronavirus-EMC. Nature. (2013) 495:251-4. doi: 10.1038/nature12005

28. Lu G, Hu Y, Wang Q, Qi J, Gao F, Li Y, et al. Molecular basis of binding between novel human coronavirus MERS-CoV and its receptor CD26. Nature. (2013) 500:227-31. doi: 10.1038/nature12328

29. Liu J, Zheng X, Tong Q, Li W, Wang B, Sutter K, et al. Overlapping and discrete aspects of the pathology and pathogenesis of the emerging human pathogenic coronaviruses SARS-CoV, MERS-CoV, and 2019-nCoV. J Med Virol. (2020) 92:491-4. doi: 10.1002/jmv.25709

30. Peiris JSM, Guan Y, Yuen KY. Severe acute respiratory syndrome. Nat Med. (2004) 10:S88-97. doi: 10.1038/nm1143

31. Hilgenfeld R, Peiris M. From SARS to MERS: 10 years of research on highly pathogenic human coronaviruses. Antiviral Res. (2013) 100:286-95. doi: 10.1016/j.antiviral.2013.08.015

32. Guan Y, Zheng BJ, He YQ, Liu XL, Zhuang ZX, Cheung CL, et al. Isolation and characterization of viruses related to the SARS coronavirus from animals in southern China. Science. (2003) 302:276-8. doi: 10.1126/science.1087139

33. Lau SKP, Woo PCY, Li KSM, Huang Y, Tsoi H-W, Wong BHL, et al. Severe acute respiratory syndrome coronavirus-like virus in Chinese horseshoe bats. Proc Natl Acad Sci USA. (2005) 102:14040-14045. doi: 10.1073/pnas.0506735102

34. Chow K-C, Hsiao C-H, Lin T-Y, Chen C-L, Chiou S-H. Detection of severe acute respiratory syndrome-associated coronavirus in pneumocytes of the lung. Am J Clin Pathol. (2004) 121:574-80. doi: 10.1309/COEDUORAQBTXBHCE

35. Shi X, Gong E, Gao D, Zhang B, Zheng J, Gao Z, et al. Severe acute respiratory syndrome associated coronavirus is detected in intestinal tissues of fatal cases. Am J Gastroenterol. (2005) 100:169-76. doi: 10.1111/j.1572-0241.2005.40377.x

36. Tsang KW, Ho PL, Ooi GC, Yee WK, Wang T, Chan-Yeung M, et al. A cluster of cases of severe acute respiratory syndrome in Hong Kong. N Engl J Med. (2003) 348:1977-85. doi: 10.1056/NEJMoa030666

37. Franks TJ, Chong PY, Chui P, Galvin JR, Lourens RM, Reid AH, et al. Lung pathology of severe acute respiratory syndrome (SARS): a study of 8 autopsy cases from Singapore. Hum Pathol. (2003) 34:743-8. doi: 10.1016/S0046-8177(03)00367-8

38. Nicholls JM, Poon LLM, Lee KC, Ng WF, Lai ST, Leung CY, et al. Lung pathology of fatal severe acute respiratory syndrome. Lancet. (2003) 361:1773-8. doi: 10.1016/S0140-6736(03)13413-7

39. Peiris JSM, Lai ST, Poon LLM, Guan Y, Yam LYC, Lim W, et al. Coronavirus as a possible cause of severe acute respiratory syndrome. Lancet. (2003) 361:1319-25. doi: 10.1016/S0140-6736(03) 13077-2

40. Sabir JSM, Lam TT-Y, Ahmed MMM, Li L, Shen Y, Abo-Aba SEM, et al. Cocirculation of three camel coronavirus species and recombination of MERSCoVs in Saudi Arabia. Science. (2016) 351:81-4. doi: 10.1126/science.aa c8608

41. Al-Omari A, Rabaan AA, Salih S, Al-Tawfiq JA, Memish ZA. MERS coronavirus outbreak: Implications for emerging viral infections. Diagn Microbiol Infect Dis. (2019) 93:265-85. doi: 10.1016/j.diagmicrobio.2018.10.011

42. Assiri A, Al-Tawfiq JA, Al-Rabeeah AA, Al-Rabiah FA, Al-Hajjar S, AlBarrak A, et al. Epidemiological, demographic, and clinical characteristics of 47 cases of Middle East respiratory syndrome coronavirus disease from Saudi Arabia: a descriptive study. Lancet Infect Dis. (2013) 13:752-61. doi: 10.1016/S1473-3099(13)70204-4

43. Lu R, Zhao X, Li J, Niu P, Yang B, Wu H, et al. Genomic characterisation and epidemiology of 2019 novel coronavirus: implications for virus origins and receptor binding. Lancet. (2020) 395:565-74. doi: 10.1016/S0140-6736(20)30251-8

44. COVID-19 Map. Johns Hopkins Coronavirus Resource Center Available online at: https://coronavirus.jhu.edu/map.html (accessed April 15, 2020). 
45. Li Q, Guan X, Wu P, Wang X, Zhou L, Tong Y, et al. Early transmission dynamics in Wuhan, China, of novel coronavirus-infected pneumonia. N Engl J Med. (2020) 382:1199-207. doi: 10.1056/NEJMoa 2001316

46. Chen N, Zhou M, Dong X, Qu J, Gong F, Han Y, et al. Epidemiological and clinical characteristics of 99 cases of 2019 novel coronavirus pneumonia in Wuhan, China: a descriptive study. Lancet. (2020) 395:507-13. doi: 10.1016/S0140-6736(20)30211-7

47. Tomasoni D, Italia L, Adamo M, Inciardi RM, Lombardi CM, Solomon SD, et al. COVID 19 and heart failure: from infection to inflammation and angiotensin II stimulation. Searching for evidence from a new disease. Eur J Heart Fail. (2020). doi: 10.1002/ejhf.1871. [Epub ahead of print].

48. Puelles VG, Lütgehetmann M, Lindenmeyer MT, Sperhake JP, Wong MN, Allweiss L, et al. Multiorgan and renal tropism of SARS-CoV-2. N Engl J Med. (2020). doi: 10.1056/NEJMc2011400. [Epub ahead of print].

49. Galbadage T, Peterson BM, Gunasekera RS. Does COVID-19 spread through droplets alone? Front Public Health. (2020) 8:163. doi: $10.3389 /$ fpubh.2020.00163

50. Sia SF, Yan L-M, Chin AWH, Fung K, Choy K-T, Wong AYL, et al. Pathogenesis and transmission of SARS-CoV-2 in golden hamsters. Nature. (2020). doi: 10.1038/s41586-020-2342-5. [Epub ahead of print].

51. Xu H, Zhong L, Deng J, Peng J, Dan H, Zeng X, et al. High expression of ACE2 receptor of 2019-nCoV on the epithelial cells of oral mucosa. Int $J$ Oral Sci. (2020) 12:8. doi: 10.1038/s41368-020-0074-x

52. Hoffmann M, Kleine-Weber H, Schroeder S, Krüger N, Herrler T, Erichsen S, et al. SARS-CoV-2 cell entry depends on ACE2 and TMPRSS2 and is blocked by a clinically proven protease inhibitor. Cell. (2020) 181:271-80. doi: 10.1016/j.cell.2020.02.052

53. Hikmet $\mathrm{F}$, Méar L, Uhlén $\mathrm{M}$, Lindskog C. The protein expression profile of ACE2 in human tissues. Cell biol. (2020) 22:16048. doi: $10.1101 / 2020.03 .31 .016048$

54. Peeri NC, Shrestha N, Rahman MS, Zaki R, Tan Z, Bibi S, et al. The SARS, MERS and novel coronavirus (COVID-19) epidemics, the newest and biggest global health threats: what lessons have we learned? Int J Epidemiol. (2020). doi: 10.1093/ije/dyaa033. [Epub ahead of print].

55. Takeuchi O, Akira S. Innate immunity to virus infection. Immunol Rev. (2009) 227:75-86. doi: 10.1111/j.1600-065X.2008.00737.x

56. Janeway CA Jr, Medzhitov R. Innate immune recognition. Annu Rev Immunol. (2002) 20:197-216. doi: 10.1146/annurev.immunol.20.083001.084359

57. Kikkert M. Innate immune evasion by human respiratory RNA viruses. $J$ Innate Immun. (2020) 12:4-20. doi: 10.1159/000503030

58. McNab F, Mayer-Barber K, Sher A, Wack A, O'Garra A. Type I interferons in infectious disease. Nat Rev Immunol. (2015) 15:87-103. doi: 10.1038/ nri3787

59. Martin TR, Frevert CW. Innate immunity in the lungs. Proc Am Thorac Soc. (2005) 2:403-11. doi: 10.1513/pats.200508-090JS

60. Murira A, Lamarre A. Type-I interferon responses: from friend to foe in the battle against chronic viral infection. Front Immunol. (2016) 7:609. doi: 10.3389/fimmu.2016.00609

61. Paolini R, Bernardini G, Molfetta R, Santoni A. NK cells and interferons. Cytokine Growth Factor Rev. (2015) 26:113-120. doi: $10.1016 /$ j.cytogfr.2014.11.003

62. Vivier E, Raulet DH, Moretta A, Caligiuri MA, Zitvogel L, Lanier LL, et al. Innate or adaptive immunity? The example of natural killer cells. Science. (2011) 331:44-9. doi: 10.1126/science.1198687

63. Mandal A, Viswanathan C. Natural killer cells: in health and disease. Hematol Oncol Stem Cell Ther. (2015) 8:47-55. doi: 10.1016/j.hemonc.2014.11.006

64. Lanier LL. NK cell recognition. Annu Rev Immunol. (2005) 23:225-74. doi: 10.1146/annurev.immunol.23.021704.1 15526

65. Long EO, Kim HS, Liu D, Peterson ME, Rajagopalan S. Controlling natural killer cell responses: integration of signals for activation and inhibition. Annu Rev Immunol. (2013) 31:227-58. doi: 10.1146/annurev-immunol-020711-075005

66. Zucchini N, Crozat K, Baranek T, Robbins SH, Altfeld M, Dalod M. Natural killer cells in immunodefense against infective agents. Expert Rev Anti Infect Ther. (2008) 6:867-85. doi: 10.1586/14787210.6.6.867
67. Tu MM, Mahmoud AB, Makrigiannis AP. Licensed and unlicensed NK cells: differential roles in cancer and viral control. Front Immunol. (2016) 7:166. doi: 10.3389/fimmu.2016.00166

68. Horton NC, Mathew PA. NKp44 and natural cytotoxicity receptors as damage-associated molecular pattern recognition receptors. Front Immunol. (2015) 6:31. doi: 10.3389/fimmu.2015.00031

69. Wensveen FM, Jelenčić V, Polić B. NKG2D: a master regulator of immune cell responsiveness. Front Immunol. (2018) 9:441. doi: 10.3389/fimmu.2018.00441

70. Huntington ND, Martinet L, Smyth MJ. DNAM-1: would the real natural killer cell please stand up! Oncotarget. (2015) 6:28537-8. doi: 10.18632/oncotarget.5952

71. Colonna M, Samaridis J. Cloning of immunoglobulin-superfamily members associated with HLA-C and HLA-B recognition by human natural killer cells. Science. (1995) 268:405-8. doi: 10.1126/science.7716543

72. D'Andrea A, Chang C, Franz-Bacon K, McClanahan T, Phillips JH, Lanier LL. Molecular cloning of NKB1. A natural killer cell receptor for HLA-B allotypes. J Immunol. (1995) 155:2306-10.

73. Wagtmann N, Biassoni R, Cantoni C, Verdiani S, Malnati MS, Vitale M, et al. Molecular clones of the p58 NK cell receptor reveal immunoglobulinrelated molecules with diversity in both the extra- and intracellular domains. Immunity. (1995) 2:439-49. doi: 10.1016/1074-7613(95)90025-X

74. Braud VM, Allan DS, O'Callaghan CA, Söderström K, D'Andrea A, Ogg GS, et al. HLA-E binds to natural killer cell receptors CD94/NKG2A, B and C. Nature. (1998) 391:795-9. doi: 10.1038/35869

75. Vance RE, Kraft JR, Altman JD, Jensen PE, Raulet DH. Mouse CD94/NKG2A is a natural killer cell receptor for the nonclassical major histocompatibility complex (MHC) class I molecule Qa-1(b). J Exp Med. (1998) 188:1841-8. doi: $10.1084 /$ jem.188.10.1841

76. Adib-Conquy M, Scott-Algara D, Cavaillon J-M, Souza-Fonseca-Guimaraes F. TLR-mediated activation of NK cells and their role in bacterial/viral immune responses in mammals. Immunol Cell Biol. (2014) 92:256-62. doi: $10.1038 /$ icb. 2013.99

77. Hammer Q, Rückert T, Borst EM, Dunst J, Haubner A, Durek P, et al. Peptide-specific recognition of human cytomegalovirus strains controls adaptive natural killer cells. Nat Immunol. (2018) 19:453-63. doi: 10.1038/s41590-018-0082-6

78. Orr MT, Sun JC, Hesslein DGT, Arase H, Phillips JH, Takai T, et al. Ly49H signaling through DAP10 is essential for optimal natural killer cell responses to mouse cytomegalovirus infection. J Exp Med. (2009) 206:80717. doi: $10.1084 / \mathrm{jem} .20090168$

79. Della Chiesa M, De Maria A, Muccio L, Bozzano F, Sivori S, Moretta L. Human NK cells and herpesviruses: mechanisms of recognition, response and adaptation. Front Microbiol. (2019) 10:2297. doi: $10.3389 /$ fmicb.2019.02297

80. Zwirner NW, Domaica CI. Cytokine regulation of natural killer cell effector functions. BioFactors. (2010) 36:274-88. doi: 10.1002/biof.107

81. Nguyen KB, Salazar-Mather TP, Dalod MY, Van Deusen JB, Wei X-Q, Liew FY, et al. Coordinated and distinct roles for IFN- $\alpha \beta$, IL-12, and IL15 regulation of NK cell responses to viral infection. J Immunol. (2002) 169:4279-87. doi: 10.4049/jimmunol.169.8.4279

82. Wu Y, Tian Z, Wei H. Developmental and functional control of natural killer cells by cytokines. Front Immunol. (2017) 8:930. doi: 10.3389/fimmu.2017.00930

83. Marquardt N, Kekäläinen E, Chen P, Kvedaraite E, Wilson JN, Ivarsson MA, et al. Human lung natural killer cells are predominantly comprised of highly differentiated hypofunctional CD69-CD56dim cells. J Allergy Clin Immunol. (2017) 139:1321-30.e4. doi: 10.1016/j.jaci.2016.07.043

84. Prlic M, Gibbs J, Jameson SC. Characteristics of NK cell migration early after vaccinia infection. J Immunol. (2005) 175:2152-7. doi: 10.4049/jimmunol.175.4.2152

85. Grégoire C, Chasson L, Luci C, Tomasello E, Geissmann F, Vivier E, et al. The trafficking of natural killer cells. Immunol Rev. (2007) 220:169-82. doi: 10.1111/j.1600-065X.2007.00563.x

86. Lee S-H, Miyagi T, Biron CA. Keeping NK cells in highly regulated antiviral warfare. Trends Immunol. (2007) 28:252-9. doi: 10.1016/j.it.2007.04.001

87. Krzewski K, Coligan JE. Human NK cell lytic granules and regulation of their exocytosis. Front Immunol. (2012) 3:335. doi: 10.3389/fimmu.2012.00335 
88. Abel AM, Yang C, Thakar MS, Malarkannan S. Natural killer cells: development, maturation, and clinical utilization. Front Immunol. (2018) 9:1869. doi: 10.3389/fimmu.2018.01869

89. Cerwenka A, Lanier LL. Natural killer cell memory in infection, inflammation and cancer. Nat Rev Immunol. (2016) 16:112-23. doi: 10.1038/nri.2015.9

90. Hammer Q, Romagnani C. About training and memory: NK-cell adaptation to viral infections. Adv Immunol. (2017) 133:171-207. doi: 10.1016/bs.ai.2016.10.001

91. Sun JC, Lanier LL. Is there natural killer cell memory and can it be harnessed by vaccination? NK cell memory and immunization strategies against infectious diseases and cancer. Cold Spring Harb Perspect Biol. (2018) 10:29538. doi: 10.1101/cshperspect.a029538

92. Pupuleku A, Costa-García M, Farré D, Hengel H, Angulo A, Muntasell A, et al. Elusive role of the CD94/NKG2C NK cell receptor in the response to cytomegalovirus: novel experimental observations in a reporter cell system. Front Immunol. (2017) 8:1317. doi: 10.3389/fimmu.2017.01317

93. Forbes CA, Scalzo AA, Degli-Esposti MA, Coudert JD. Ly49Cdependent control of MCMV Infection by NK cells is cis-regulated by MHC Class I molecules. PLoS Pathog. (2014) 10:e1004161. doi: 10.1371/journal.ppat.1004161

94. Della Chiesa M, Sivori S, Carlomagno S, Moretta L, Moretta A. Activating KIRs and NKG2C in viral infections: toward NK cell memory? Front Immunol. (2015) 6:573. doi: 10.3389/fimmu.2015.00573

95. Cooper MA, Elliott JM, Keyel PA, Yang L, Carrero JA, Yokoyama WM. Cytokine-induced memory-like natural killer cells. Proc Natl Acad Sci USA. (2009) 106:1915-19. doi: 10.1073/pnas.0813192106

96. Orange JS. Natural killer cell deficiency. J Allergy Clin Immunol. (2013) 132:515-25. doi: 10.1016/j.jaci.2013.07.020

97. Biron CA, Byron KS, Sullivan JL. Severe herpesvirus infections in an adolescent without natural killer cells. N Engl J Med. (1989) 320:1731-5. doi: 10.1056/NEJM198906293202605

98. Rolston KVI. Infections in cancer patients with solid tumors: a review. Infect Dis Ther. (2017) 6:69-83. doi: 10.1007/s40121-017-0146-1

99. Rotstein C. Viral infections in cancer patients. In: D. J. Higby, editor. The Cancer Patient Supportive Care Cancer Treatment Research. Boston, MA: Springer US (2020). p. 57-97. doi: 10.1007/978-1-4613-2567-3_3

100. Lee J-C, Lee K-M, Kim D-W, Heo DS. Elevated TGF-betal secretion and down-modulation of NKG2D underlies impaired NK cytotoxicity in cancer patients. J Immunol. (2004) 172:7335-40. doi: 10.4049/jimmunol.172.12.7335

101. Tai L-H, de Souza CT, Belanger S, Ly L, Alkayyal A a., Zhang J, et al., Lam T, Breitbach CJ, et al. Preventing postoperative metastatic disease by inhibiting surgery-induced dysfunction in natural killer cells. Cancer Res. (2013) 73:97-107. doi: 10.1158/0008-5472.CAN-12-1993

102. Ardolino M, Azimi CS, Iannello A, Trevino TN, Horan L, Zhang L, et al. Cytokine therapy reverses NK cell anergy in MHC-deficient tumors. J Clin Invest. (2014) 124:4781-94. doi: 10.1172/JCI74337

103. Angka L, Martel AB, Kilgour M, Jeong A, Sadiq M, de Souza CT, et al. Natural killer cell IFN $\gamma$ secretion is profoundly suppressed following colorectal cancer surgery. Ann Surg Oncol. (2018) 25:3747-54. doi: 10.1245/s10434-018-6691-3

104. Hijano DR, Maron G, Hayden RT. Respiratory viral infections in patients with cancer or undergoing hematopoietic cell transplant. Front Microbiol. (2018) 9:3097. doi: 10.3389/fmicb.2018.03097

105. Zhang L, Zhu F, Xie L, Wang C, Wang J, Chen R, et al. Clinical characteristics of COVID-19-infected cancer patients: A retrospective case study in three hospitals within Wuhan, China. Ann Oncol. (2020) 31:894901. doi: 10.1016/j.annonc.2020.03.296

106. Liang W, Guan W, Chen R, Wang W, Li J, Xu K, et al. Cancer patients in SARS-CoV-2 infection: a nationwide analysis in China. Lancet Oncol. (2020) 21:335-37. doi: 10.1016/S1470-2045(20) 30096-6

107. Leng J, Goldstein DR. Impact of aging on viral infections. Microbes Infect. (2010) 12:1120-4. doi: 10.1016/j.micinf.2010.08.009

108. Fang M, Roscoe F, Sigal LJ. Age-dependent susceptibility to a viral disease due to decreased natural killer cell numbers and trafficking. J Exp Med. (2010) 207:2369-81. doi: 10.1084/jem.20100282
109. Ginaldi L, De Martinis M, D’Ostilio A, Marini L, Loreto F, Modesti M, et al. Changes in the expression of surface receptors on lymphocyte subsets in the elderly: quantitative flow cytometric analysis. Am J Hematol. (2001) 67:63-72. doi: 10.1002/ajh.1082

110. Yan J, Greer JM, Hull R, O'Sullivan JD, Henderson RD, Read SJ, et al. The effect of ageing on human lymphocyte subsets: comparison of males and females. Immun Ageing. (2010) 7:4. doi: 10.1186/1742-4933-7-4

111. Przemska-Kosicka A, Childs CE, Maidens C, Dong H, Todd S, Gosney MA, et al. Age-related changes in the natural killer cell response to seasonal influenza vaccination are not influenced by a synbiotic: a randomised controlled trial. Front Immunol. (2018) 9:591. doi: 10.3389/fimmu.2018.00591

112. O'Shea D, Hogan AE. Dysregulation of natural killer cells in obesity. Cancers. (2019) 11:573. doi: 10.3390/cancers11040573

113. Kass DA, Duggal P, Cingolani O. Obesity could shift severe COVID-19 disease to younger ages. Lancet. (2020) 395:1544-5. doi: 10.1016/S0140-6736(20)31024-2

114. CDC. Coronavirus Disease 2019 (COVID-19). Centers for Disease Control and Prevention (2020) Available online at: https://www.cdc.gov/coronavirus/ 2019-ncov/need-extra-precautions/groups-at-higher-risk.html (accessed April 6, 2020).

115. Minotti C, Tirelli F, Barbieri E, Giaquinto C, Donà D. How is immunosuppressive status affecting children and adults in SARSCoV-2 infection? A systematic review. J Infect. (2020) 81:e61-6. doi: 10.1016/j.jinf.2020.04.026

116. Vijay R, Perlman S. Middle east respiratory syndrome and severe acute respiratory syndrome. Curr Opin Virol. (2016) 16:70-6. doi: 10.1016/j.coviro.2016.01.011

117. Siu K-L, Kok K-H, Ng M-HJ, Poon VKM, Yuen K-Y, Zheng B-J, et al. Severe acute respiratory syndrome coronavirus $\mathrm{M}$ protein inhibits type I interferon production by impeding the formation of TRAF3.TANK.TBK1/IKKepsilon complex. J Biol Chem. (2009) 284:16202-9. doi: 10.1074/jbc.M109.008227

118. Channappanavar R, Fehr AR, Vijay R, Mack M, Zhao J, Meyerholz DK, et al. Dysregulated type I Interferon and inflammatory monocyte-macrophage responses cause lethal pneumonia in SARS-CoV-infected mice. Cell Host Microbe. (2016) 19:181-93. doi: 10.1016/j.chom.2016.01.007

119. Glass WG, Subbarao K, Murphy B, Murphy PM. Mechanisms of host defense following severe acute respiratory syndrome-coronavirus (SARS$\mathrm{CoV}$ ) pulmonary infection of mice. J Immunol. (2004) 173:4030-9. doi: 10.4049/jimmunol.173.6.4030

120. Chen J, Lau YF, Lamirande EW, Paddock CD, Bartlett JH, Zaki SR, et al. Cellular immune responses to severe acute respiratory syndrome coronavirus (SARS-CoV) infection in senescent BALB/c mice: CD4+ T cells are important in control of SARS-CoV infection. J Virol. (2010) 84:1289-301. doi: 10.1128/JVI.01281-09

121. Subbarao K, McAuliffe J, Vogel L, Fahle G, Fischer S, Tatti K, et al. Prior infection and passive transfer of neutralizing antibody prevent replication of severe acute respiratory syndrome coronavirus in the respiratory tract of mice. J Virol. (2004) 78:3572-7. doi: 10.1128/JVI.78.7.3572-3577.2004

122. Wentworth DE, Gillim-Ross L, Espina N, Bernard KA. Mice susceptible to SARS coronavirus. Emerg Infect Dis. (2004) 10:1293-6. doi: 10.3201/eid1007.031119

123. Roberts A, Deming D, Paddock CD, Cheng A, Yount B, Vogel L, et al. A mouse-adapted SARS-coronavirus causes disease and mortality in BALB/c mice. PLoS Pathog. (2007) 3:e5. doi: 10.1371/journal.ppat.0030005

124. Israelow B, Song E, Mao T, Lu P, Meir A, Liu F, et al. Mouse model of SARS-CoV-2 reveals inflammatory role of type I interferon signaling. bioRxiv [Preprint]. (2020). doi: 10.1101/2020.05.27.118893

125. Bao L, Deng W, Huang B, Gao H, Liu J, Ren L, et al. The pathogenicity of SARS-CoV-2 in hACE2 transgenic mice. Nature. (2020). doi: 10.1038/s41586-020-2312-y. [Epub ahead of print].

126. Dinnon KH, Leist SR, Schäfer A, Edwards CE, Martinez DR, Montgomery $\mathrm{SA}$, et al. A mouse-adapted SARS-CoV-2 model for the evaluation of COVID-19 medical countermeasures. bioRxiv [Preprint]. (2020). doi: 10.1101/2020.05.06.081497

127. Zheng M, Gao Y, Wang G, Song G, Liu S, Sun D, et al. Functional exhaustion of antiviral lymphocytes in COVID-19 patients. Cell Mol Immunol. (2020) 17:533-5. doi: 10.1038/s41423-020-0402-2 
128. Liao M, Liu Y, Yuan J, Wen Y, Xu G, Zhao J, et al. Single-cell landscape of bronchoalveolar immune cells in patients with COVID-19. Nat Med. (2020) 26:842-4. doi: 10.1038/s41591-020-0901-9

129. Carvelli J, Demaria O, Vély F, Batista L, Benmansour NC, Fares J, et al. Identification of immune checkpoints in COVID-19. Nat Res. (2020). doi: $10.21203 /$ rs.3.rs-27340/v1

130. Wilk AJ, Rustagi A, Zhao NQ, Roque J, Martinez-Colon GJ, McKechnie $\mathrm{JL}$, et al. A single-cell atlas of the peripheral immune response to severe COVID-19. medRxiv [Preprint]. (2020). doi: 10.1038/s41591-020-0944-y

131. Giamarellos-Bourboulis EJ, Netea MG, Rovina N, Akinosoglou K, Antoniadou A, Antonakos N, et al. Complex immune dysregulation in COVID-19 patients with severe respiratory failure. Cell Host Microbe. (2020) 27:992-1000.e3. doi: 10.1016/j.chom.2020.04.009

132. National Research Project for SARS, Beijing Group. The involvement of natural killer cells in the pathogenesis of severe acute respiratory syndrome. Am J Clin Pathol. (2004) 121:507-11. doi: 10.1309/WPK7Y2XKNF4CBF3R

133. Dong Q-M, He Z-P, Zhuang H, Song S-J, Dai W-S, Zhang S-P, et al. Dynamics of peripheral blood B lymphocytes and natural killer cells in patients with severe acute respiratory syndrome. Zhonghua Liu Xing Bing Xue Za Zhi. (2004) 25:695-7.

134. Zaki AM, van Boheemen S, Bestebroer TM, Osterhaus ADME, Fouchier RAM. Isolation of a novel coronavirus from a man with pneumonia in Saudi Arabia. N Engl J Med. (2012) 367:1814-20. doi: 10.1056/NEJMoa1211721

135. Cunha CB, Opal SM. Middle East respiratory syndrome (MERS): a new zoonotic viral pneumonia. Virulence. (2014) 5:650-4. doi: 10.4161/viru.32077

136. Al-Tawfiq JA, Hinedi K, Abbasi S, Babiker M, Sunji A, Eltigani M. Hematologic, hepatic, and renal function changes in hospitalized patients with Middle East respiratory syndrome coronavirus. Int J Lab Hematol. (2017) 39:272-8. doi: 10.1111/ijlh.12620

137. McKechnie JL, Blish CA. The innate immune system: fighting on the front lines or fanning the flames of COVID-19? Cell Host Microbe. (2020) 27:8639. doi: 10.1016/j.chom.2020.05.009

138. Huang KJ, Su IJ, Theron M, Wu YC, Lai SK, Liu CC, et al. An interferongamma-related cytokine storm in SARS patients. J Med Virol. (2005) 75:18594. doi: $10.1002 / j m v .20255$

139. Kleinertz H, Hepner-Schefczyk M, Ehnert S, Claus M, Halbgebauer R, Boller L, et al. Circulating growth/differentiation factor 15 is associated with human CD56 natural killer cell dysfunction and nosocomial infection in severe systemic inflammation. EBioMedicine. (2019) 43:380-91. doi: 10.1016/j.ebiom.2019.04.018

140. Jobin G, Rodriguez-Suarez R, Betito K. Association between natural killer cell activity and colorectal cancer in high-risk subjects undergoing colonoscopy. Gastroenterology. (2017) 153:980-7. doi: 10.1053/j.gastro.2017.06.009

141. Gu J, Gong E, Zhang B, Zheng J, Gao Z, Zhong Y, et al. Multiple organ infection and the pathogenesis of SARS. J Exp Med. (2005) 202:415-24. doi: 10.1084/jem.20050828

142. Bost P, Giladi A, Liu Y, Bendjelal Y, Xu G, David E, et al. Host-viral infection maps reveal signatures of severe COVID-19 patients. Cell. (2020) 181. doi: 10.1016/j.cell.2020.05.006

143. Law HKW, Cheung CY, Ng HY, Sia SF, Chan YO, Luk W, et al. Chemokine up-regulation in SARS-coronavirus-infected, monocyte-derived human dendritic cells. Blood. (2005) 106:2366-74. doi: 10.1182/blood-2004-10-4166

144. Yen Y-T, Liao F, Hsiao C-H, Kao C-L, Chen Y-C, Wu-Hsieh BA. Modeling the early events of severe acute respiratory syndrome coronavirus infection in vitro. J Virol. (2006) 80:2684-93. doi: 10.1128/JVI.80.6.2684-2693.2006

145. Chen J, Lau YF, Lamirande EW, Paddock CD, Bartlett JH, Zaki SR, et al. Cellular immune responses to severe acute respiratory syndrome coronavirus (SARS-CoV) infection in senescent BALB/c mice: CD4 T Cells are important in control of SARS-CoV infection. J Virol. (2010) 84:1289-301. doi: 10.1128/jvi.01281-09

146. Kong SL, Chui P, Lim B, Salto-Tellez M. Elucidating the molecular physiopathology of acute respiratory distress syndrome in severe acute respiratory syndrome patients. Virus Res. (2009) 145:260-9. doi: 10.1016/j.virusres.2009.07.014

147. Wilson JG, Simpson LJ, Ferreira A-M, Rustagi A, Roque J, Asuni A, et al. Cytokine profile in plasma of severe COVID-19 does not differ from ARDS and sepsis. medRxiv [Preprint]. (2020). doi: 10.1101/2020.05.15.20103549
148. Rajaram S, Canaday LM, Ochayon DE, Rangel KM, Ali A, Gyurova IE, et al. The promise and peril of natural killer cell therapies in pulmonary infection. Immunity. (2020) 52:887-9. doi: 10.1016/j.immuni.2020.04.018

149. Chiche L, Forel J-M, Thomas G, Farnarier C, Vely F, Bléry M, et al. The role of natural killer cells in sepsis. J Biomed Biotechnol. (2011) 2011:986491. doi: $10.1155 / 2011 / 986491$

150. Forel J-M, Chiche L, Thomas G, Mancini J, Farnarier C, Cognet C, et al. Phenotype and functions of natural killer cells in critically-ill septic patients. PLoS One. (2012) 7:e50446. doi: 10.1371/journal.pone.0050446

151. Giannikopoulos G, Antonopoulou A, Kalpakou G, Makaritsis K, Panou C, Papadomichelakis E, et al. The functional role of natural killer cells early in clinical sepsis. APMIS. (2013) 121:329-336. doi: 10.1111/apm.12002

152. Guo Y, Patil NK, Luan L, Bohannon JK, Sherwood ER. the biology of natural killer cells during sepsis. Immunology. (2018) 153:190-202. doi: $10.1111 / \mathrm{imm} .12854$

153. Forni D, Cagliani R, Clerici M, Sironi M. Molecular evolution of human coronavirus genomes. Trends Microbiol. (2017) 25:35-48. doi: 10.1016/j.tim.2016.09.001

154. Zhang B, Liu S, Tan T, Huang W, Dong Y, Chen L, et al. Treatment with convalescent plasma for critically ill patients with SARS-CoV-2 infection. Chest. (2020) doi: 10.1016/j.chest.2020.03.039. [Epub ahead of print].

155. Zhang H, Penninger JM, Li Y, Zhong N, Slutsky AS. Angiotensin-converting enzyme 2 (ACE2) as a SARS-CoV-2 receptor: molecular mechanisms and potential therapeutic target. Intensive Care Med. (2020) 46:586-90. doi: $10.1007 / \mathrm{s} 00134-020-05985-9$

156. Kupferschmidt K, Cohen J. Race to find COVID-19 treatments accelerates. Science. (2020) 367:1412-3. doi: 10.1126/science.367.6485.1412

157. Elfiky AA. Ribavirin, Remdesivir, Sofosbuvir, Galidesivir, and Tenofovir against SARS-CoV-2 RNA dependent RNA polymerase (RdRp): A molecular docking study. Life Sci. (2020) 2020:117592. doi: 10.1016/j.lfs.2020.117592

158. Shimasaki N, Jain A, Campana D. NK cells for cancer immunotherapy. Nat Rev Drug Disc. (2020) 19:200-18. doi: 10.1038/s41573-019-0052-1

159. Fujisaki H, Kakuda H, Shimasaki N, Imai C, Ma J, Lockey T, et al. Expansion of highly cytotoxic human natural killer cells for cancer cell therapy. Cancer Res. (2009) 69:4010-7. doi: 10.1158/0008-5472.CAN-08-3712

160. Cooley S, He F, Bachanova V, Vercellotti GM, DeFor TE, Curtsinger JM, et al. First-in-human trial of rhIL-15 and haploidentical natural killer cell therapy for advanced acute myeloid leukemia. Blood Adv. (2019) 3:1970-80. doi: 10.1182/bloodadvances.2018028332

161. Hu W, Wang G, Huang D, Sui M, Xu Y. Cancer Immunotherapy based on natural killer cells: current progress and new opportunities. Front Immunol. (2019) 10:1205. doi: 10.3389/fimmu.2019.01205

162. Celularity, Inc. Celularity Announces FDA Clearance of IND Application for CYNK-001 in Coronavirus, First in Cellular Therapy. PR Newswire. (2020). Available online at: 4

163. Han J, Chu J, Keung Chan W, Zhang J, Wang Y, Cohen JB, et al. CARengineered NK cells targeting wild-type EGFR and EGFRvIII enhance killing of glioblastoma and patient-derived glioblastoma stem cells. Sci Rep. (2015) 5:11483. doi: 10.1038/srep11483

164. Liu E, Marin D, Banerjee P, Macapinlac HA, Thompson P, Basar R, et al. Use of CAR-transduced natural killer cells in CD19-positive lymphoid tumors. N Engl J Med. (2020) 382:545-53. doi: 10.1056/NEJMoa19 10607

165. Wang W, Jiang J, Wu C. CAR-NK for tumor immunotherapy: Clinical transformation and future prospects. Cancer Lett. (2020) 472:175-80. doi: 10.1016/j.canlet.2019.11.033

166. Parihar R, Rivas C, Huynh M, Omer B, Lapteva N, Metelitsa LS, et al. NK cells expressing a chimeric activating receptor eliminate MDSCs and rescue impaired CAR-T cell activity against solid tumors. Cancer Immunol Res. (2019) 7:363-75. doi: 10.1158/2326-6066.CIR-18-0572

167. Hammer Q, Rückert T, Romagnani C. Natural killer cell specificity for viral infections. Nat Immunol. (2018) 19:800-8. doi: 10.1038/s41590-018-0163-6

168. Seay K, Church C, Zheng JH, Deneroff K, Ochsenbauer C, Kappes JC, et al. In vivo activation of human NK cells by treatment with an interleukin-15 superagonist potently inhibits acute in vivo HIV-1 infection in humanized mice. J Virol. (2015) 89:6264-74. doi: 10.1128/JVI.00563-15

169. Muro S, Taha R, Tsicopoulos A, Olivenstein R, Tonnel AB, Christodoulopoulos P, et al. Expression of IL-15 in inflammatory 
pulmonary diseases. J Allergy Clin Immunol. (2001) 108:970-5. doi: 10.1067/mai.2001.119556

170. Noroozi R, Branicki W, Pyrc K, Łabaj PP, Pośpiech E, Taheri M, GhafouriFard S. Altered cytokine levels and immune responses in patients with SARS-CoV-2 infection and related conditions. Cytokine. (2020) 2020:155143. doi: $10.1016 /$ j.cyto.2020.155143

171. Clay CC, Donart N, Fomukong N, Knight JB, Overheim K, Tipper J, et al. Severe acute respiratory syndrome-coronavirus infection in aged nonhuman primates is associated with modulated pulmonary and systemic immune responses. Immun Ageing. (2014) 11:4. doi: 10.1186/1742-4933-11-4

172. Sterner RM, Sakemura R, Cox MJ, Yang N, Khadka RH, Forsman $\mathrm{CL}$, et al. GM-CSF inhibition reduces cytokine release syndrome and neuroinflammation but enhances CAR-T cell function in xenografts. Blood. (2019) 133:697-709. doi: 10.1182/blood-2018-10-881722

173. Zhou Y, Fu B, Zheng X, Wang D, Zhao C, Qi Y, et al. Pathogenic T cells and inflammatory monocytes incite inflammatory storm in severe COVID-19 patients. Natl Sci Rev. (2020) nwaa041. doi: 10.1093/nsr/nwaa041

174. Frieman M, Heise M, Baric R. SARS coronavirus and innate immunity. Virus Res. (2008) 133:101-12. doi: 10.1016/j.virusres.2007.03.015

175. Müller L, Aigner P, Stoiber D. Type I interferons and natural killer cell regulation in cancer. Front Immunol. (2017) 8:304. doi: 10.3389/fimmu.2017.00304

176. Eckert K, Schmitt M, Garbin F, Wahn U, Maurer HR. Thymosin alpha 1 effects, in vitro, on lymphokine-activated killer cells from patients with primary immunodeficiencies: preliminary results. Int J Immunopharmacol. (1994) 16:1019-25. doi: 10.1016/0192-0561(94)90081-7

177. King R, Tuthill C. Immune modulation with thymosin alpha 1 treatment. Vitam Horm. (2016) 102:151-78. doi: 10.1016/bs.vh.2016.04.003

178. Cinatl J, Morgenstern B, Bauer G, Chandra P, Rabenau H, Doerr HW. Treatment of SARS with human interferons. Lancet. (2003) 362:293-4. doi: 10.1016/S0140-6736(03)13973-6

179. Hung IFN, Lung KC, Tso EYK, Liu R, Chung TWH, Chu MY, et al. Triple combination of interferon beta-1b, lopinavir-ritonavir, and ribavirin in the treatment of patients admitted to hospital with COVID-19: an open-label, randomised, phase 2 trial. Lancet. (2020) 395-1695-704. doi: 10.1016/S0140-6736(20)31042-4

180. Teijaro JR. Type I interferons in viral control and immune regulation. Curr Opin Virol. (2016) 16:31-40. doi: 10.1016/j.coviro.2016.01.001

181. Major J, Crotta S, Llorian M, McCabe TM, Gad HH, Hartmann R, et al. Type I and III interferons disrupt lung epithelial repair during recovery from viral infection. bioRxiv [Preprint]. (2020) doi: 10.1101/2020.05.05.078360

182. Lazear HM, Schoggins JW, Diamond MS. Shared and distinct functions of type I and type III interferons. Immunity. (2019) 50:907-23. doi: 10.1016/j.immuni.2019.03.025

183. Davidson S, McCabe TM, Crotta S, Gad HH, Hessel EM, Beinke S, et al. IFN $\lambda$ is a potent anti-influenza therapeutic without the inflammatory side effects of IFN $\alpha$ treatment. EMBO Mol Med. (2016) 8:1099-112. doi: 10.15252/emmm.201606413

184. Galani IE, Triantafyllia V, Eleminiadou EE, Koltsida O, Stavropoulos $A$, Manioudaki $M$, et al. Interferon- $\lambda$ mediates non-redundant front-line antiviral protection against influenza virus infection without compromising host fitness. Immunity. (2017) 46:875-90.e6. doi: 10.1016/j.immuni.2017.04.025

185. de Groen RA, Boltjes A, Hou J, Liu B-S, McPhee F, Friborg J, et al. IFN- $\lambda$ mediated IL-12 production in macrophages induces IFN- $\gamma$ production in human NK cells. Eur J Immunol. (2015) 45:250-9. doi: 10.1002/eji.201444903

186. Broggi A, Ghosh S, Sposito B, Spreafico R, Balzarini F, Lo Cascio A, et al. Type III interferons disrupt the lung epithelial barrier upon viral recognition. bioRxiv [Preprint]. (2020). doi: 10.1101/2020.05.05.077867

187. Berraondo P, Sanmamed MF, Ochoa MC, Etxeberria I, Aznar MA, PérezGracia JL, et al. Cytokines in clinical cancer immunotherapy. British J. Cancer. (2019) 120:6-15. doi: 10.1038/s41416-018-0328-y

188. Wrangle JM, Velcheti V, Patel MR, Garrett-Mayer E, Hill EG, Ravenel JG, et al. ALT-803, an IL-15 superagonist, in combination with nivolumab in patients with metastatic non-small cell lung cancer: a nonrandomised, open-label, phase 1b trial. Lancet Oncol. (2018) 19:694-704. doi: $10.1016 / \mathrm{S} 1470-2045(18) 30148-7$
189. Robinson TO, Schluns KS. The potential and promise of IL-15 in immuno-oncogenic therapies. Immunol Lett. (2017) 190:159-68. doi: 10.1016/j.imlet.2017.08.010

190. Kahan SM, Wherry EJ, Zajac AJ. T cell exhaustion during persistent viral infections. Virology. (2015) 479-480:180-93. doi: 10.1016/j.virol.2014.12.033

191. Wei SC, Duffy CR, Allison JP. Fundamental mechanisms of immune checkpoint blockade therapy. Cancer Discov. (2018) 8:1069-86. doi: 10.1158/2159-8290.CD-18-0367

192. Sharpe AH. Introduction to checkpoint inhibitors and cancer immunotherapy. Immunol Rev. (2017) 276:5-8. doi: 10.1111/imr.12531

193. Hsu J, Hodgins JJ, Marathe M, Nicolai CJ, Bourgeois-Daigneault MC, Trevino TN, et al. Contribution of NK cells to immunotherapy mediated by PD-1/PD-L1 blockade. J Clin Invest. (2018) 128:4654-68. doi: 10.1172/JCI99317

194. Bi J, Tian Z. NK cell dysfunction and checkpoint immunotherapy. Front Immunol. (2019) 10:1999. doi: 10.3389/fimmu.2019.01999

195. Qin W, Hu L, Zhang X, Jiang S, Li J, Zhang Z, et al. The diverse function of PD-1/PD-L pathway beyond cancer. Front Immunol. (2019) 10:2298. doi: 10.3389/fimmu.2019.02298

196. Hodgins JJ, Khan ST, Park MM, Auer RC, Ardolino M. Killers 2.0: NK cell therapies at the forefront of cancer control. J Clin Invest. (2019) 129:3499510. doi: 10.1172/JCI129338

197. Khan M, Arooj S, Wang H. NK cell-based immune checkpoint inhibition. Front Immunol. (2020) 11:167. doi: 10.3389/fimmu.2020.00167

198. André P, Denis C, Soulas C, Bourbon-Caillet C, Lopez J, Arnoux T, et al. Anti-NKG2A mAb is a checkpoint inhibitor that promotes anti-tumor immunity by unleashing both T and NK Cells. Cell. (2018) 175:1731-43.e13. doi: 10.1016/j.cell.2018.10.014

199. van Montfoort N, Borst L, Korrer MJ, Sluijter M, Marijt KA, Santegoets SJ, et al. NKG2A blockade potentiates CD8 T cell immunity induced by cancer vaccines. Cell. (2018) 175:1744-55.e15. doi: 10.1016/j.cell.2018.10.028

200. Li F, Wei H, Wei H, Gao Y, Xu L, Yin W, et al. Blocking the natural killer cell inhibitory receptor NKG2A increases activity of human natural killer cells and clears hepatitis B virus infection in mice. Gastroenterology. (2013) 144:392-401. doi: 10.1053/j.gastro.2012.10.039

201. Antonioli L, Fornai M, Pellegrini C, Blandizzi C. NKG2A and COVID19: another brick in the wall. Cell Mol Immunol. (2020) 17:672-4. doi: 10.1038/s41423-020-0450-7

202. Shifrin N, Raulet DH, Ardolino M. NK cell self tolerance, responsiveness and missing self recognition. Semin Immunol. (2014) 26:138-44. doi: $10.1016 /$ j.smim.2014.02.007

203. Netea MG, Joosten LAB, Latz E, Mills KHG, Natoli G, Stunnenberg HG, et al. Trained immunity: a program of innate immune memory in health and disease. Science. (2016) 352:aaf1098. doi: 10.1126/science.aaf1098

204. Moorlag SJCFM, Röring RJ, Joosten LAB, Netea MG. The role of the interleukin-1 family in trained immunity. Immunol Rev. (2018) 281:28-39. doi: $10.1111 /$ imr.12617

205. Kar UK, Joosten LAB. Training the trainable cells of the immune system and beyond. Nat Immunol. (2020) 21:115-9. doi: 10.1038/s41590-019-0583-y

206. O'Neill LAJ, Netea MG. BCG-induced trained immunity: can it offer protection against COVID-19? Nat Rev Immunol. (2020) 20:335-7. doi: $10.1038 /$ s41577-020-0337-y

207. Kleinnijenhuis J, Quintin J, Preijers F, Joosten LAB, Jacobs C, Xavier RJ, et al. BCG-induced trained immunity in NK cells: role for nonspecific protection to infection. Clin Immunol. (2014) 155:213-9. doi: 10.1016/j.clim.2014.10.005

208. Arts RJW, Moorlag SJCFM, Novakovic B, Li Y, Wang SY, Oosting M, et al. $B C G$ vaccination protects against experimental viral infection in humans through the induction of cytokines associated with trained immunity. Cell Host Microbe. (2018) 23:89-100.e5. doi: 10.1016/j.chom.2017.12.010

209. Netea MG, Giamarellos-Bourboulis EJ, Domínguez-Andrés J, Curtis N, van Crevel R, van de Veerdonk FL, et al. Trained immunity: a tool for reducing susceptibility to and the severity of SARS-CoV-2 infection. Cell. (2020) 181:969-77. doi: 10.1016/j.cell.2020.04.042

210. Curtis N, Sparrow A, Ghebreyesus TA, Netea MG. Considering BCG vaccination to reduce the impact of COVID-19. Lancet. (2020) 395:1545-6. doi: $10.1016 / \mathrm{S} 0140-6736(20) 31025-4$ 
211. Shet A, Ray D, Malavige N, Santosham M, Bar-Zeev N. Differential COVID19-attributable mortality and BCG vaccine use in countries. medRxiv [Preprint]. (2020) doi: 10.1101/2020.04.01.20049478

212. Hamiel U, Kozer E, Youngster I. SARS-CoV-2 rates in BCGvaccinated and unvaccinated young adults. JAMA. (2020) 13:e208189. doi: 10.1001/jama.2020.8189

213. Brook B, Harbeson DJ, Shannon CP, Cai B, He D, Ben-Othman R, et al. BCG vaccination-induced emergency granulopoiesis provides rapid protection from neonatal sepsis. Sci Transl Med. (2020) 12:eaax4517. doi: 10.1126/scitranslmed.aax4517

214. Dalgleish A. Have I found the missing ingredient in a coronavirus vaccine? The Daily Telegraph. (2020) Available online at: https://www.telegraph.co. uk/news/2020/03/30/have-found-missing-ingredient-coronavirus-vaccine/ (accessed April 12, 2020).

215. Dalgleish AG, Stebbing J, Adamson DJ, Arif SS, Bidoli P, Chang D, et al. Randomised, open-label, phase II study of gemcitabine with and without IMM-101 for advanced pancreatic cancer. Br J Cancer. (2016) 115:789-96. doi: $10.1038 /$ bjc. 2016.271

216. Dalgleish AG, Stebbing J. Five year survival in patients with metastatic melanoma receiving IMM-101. Ann Oncol. (2015) 26:viii5. doi: 10.1093/annonc/mdv514.17

217. Dalgleish AG, Mudan S, Fusi A. Enhanced effect of checkpoint inhibitors when given after or together with IMM-101: significant responses in four advanced melanoma patients with no additional major toxicity. J Transl Med. (2018) 16:227. doi: 10.1186/s12967-018-1602-8

218. Patel MC, Shirey KA, Pletneva LM, Boukhvalova MS, Garzino-Demo A, Vogel SN, et al. Novel drugs targeting toll-like receptors for antiviral therapy. Future Virol. (2014) 9:811-829. doi: 10.2217/fvl.14.70

219. Bode C, Zhao G, Steinhagen F, Kinjo T, Klinman DM. CpG DNA as a vaccine adjuvant. Expert Rev Vaccines. (2011) 10:499-511. doi: 10.1586/erv.10.174

220. Bao M, Zhang Y, Wan M, Dai L, Hu X, Wu X, et al. Anti-SARS-CoV immunity induced by a novel CpG oligodeoxynucleotide. Clin Immunol. (2006) 118:180-7. doi: 10.1016/j.clim.2005.09.014

221. Carr AC, Maggini S. Vitamin C and immune function. Nutrients. (2017) 9:1211. doi: 10.3390/nu9111211

222. Heuser G, Vojdani A. Enhancement of natural killer cell activity and $\mathrm{T}$ and $\mathrm{B}$ cell function by buffered vitamin $\mathrm{C}$ in patients exposed to toxic chemicals: the role of protein kinase-C. Immunopharmacol. (1997) 19:291-312. doi: 10.3109/089239797090 46977

223. Kim H, Jang M, Kim Y, Choi J, Jeon J, Kim J, et al. Red ginseng and vitamin C increase immune cell activity and decrease lung inflammation induced by influenza A virus/H1N1 infection. J Pharm Pharmacol. (2016) 68:406-20. doi: $10.1111 /$ jphp.12529

224. Cai Y, Li YF, Tang LP, Tsoi B, Chen M, Chen H, et al. A new mechanism of vitamin $\mathrm{C}$ effects on $\mathrm{A} / \mathrm{FM} / 1 / 47(\mathrm{H} 1 \mathrm{~N} 1)$ virus-induced pneumonia in restraint-stressed mice. Biomed Res Int. (2015) 2015:675149. doi: 10.1155/2015/675149

225. Traber MG, Stevens JF. Vitamins C and E: beneficial effects from a mechanistic perspective. Free Radic Biol Med. (2011) 51:1000-13. doi: 10.1016/j.freeradbiomed.2011.05.017

226. May JM, Harrison FE. Role of vitamin C in the function of the vascular endothelium. Antioxid Redox Signal. (2013) 19:2068-83. doi: 10.1089/ars.2013.5205

227. Kellner M, Noonepalle S, Lu Q, Srivastava A, Zemskov E, Black SM. ROS signaling in the pathogenesis of acute lung injury (ALI) and acute respiratory distress syndrome (ARDS). Adv Exp Med Biol. (2017) 967:10537. doi: 10.1007/978-3-319-63245-2_8

228. Teixeira A, Carrié AS, Généreau T, Herson S, Cherin P. Vitamin C deficiency in elderly hospitalized patients. Am J Med. (2001) 111:502. doi: 10.1016/S0002-9343(01)00893-2

229. Rodemeister S, Duquesne M, Adolph M, Nohr D, Biesalski HK, Unertl K. Massive and long-lasting decrease in vitamin C plasma levels as a consequence of extracorporeal circulation. Nutrition. (2014) 30:673-8. doi: 10.1016/j.nut.2013.10.026

230. Marik PE. Vitamin C for the treatment of sepsis: the scientific rationale. Pharmacol Ther. (2018) 189:63-70. doi: 10.1016/j.pharmthera.2018.04.007
231. Hemilä H, Chalker E. Vitamin C for preventing and treating the common cold. Cochrane Database Syst Rev. (2013). doi: 10.1002/14651858.CD000980.pub4

232. Hemilä H, Chalker E. Vitamin C can shorten the length of stay in the ICU: a meta-analysis. Nutrients. (2019) 11:708. doi: 10.3390/nu11040708

233. Chambial S, Dwivedi S, Shukla KK, John PJ, Sharma P. Vitamin C in disease prevention and cure: an overview. Indian J Clin Biochem. (2013) 28:314-28. doi: 10.1007/s12291-013-0375-3

234. Mehta P, McAuley DF, Brown M, Sanchez E, Tattersall RS, Manson JJ. COVID-19: consider cytokine storm syndromes and immunosuppression. Lancet. (2020) 395:1033-4. doi: 10.1016/S0140-6736(20)30628-0

235. Vabret N, Britton GJ, Gruber C, Hegde S, Kim J, Kuksin M, et al. Immunology of COVID-19: current state of the science. Immunity. (2020) 52:910-41. doi: 10.1016/j.immuni.2020.05.002

236. Merad M, Martin JC. Pathological inflammation in patients with COVID19: a key role for monocytes and macrophages. Nat Rev Immunol. (2020) doi: 10.1038/s41577-020-0331-4

237. Nile SH, Nile A, Qiu J, Li L, Jia X, Kai G. COVID-19: pathogenesis, cytokine storm and therapeutic potential of interferons. Cytokine Growth Factor Rev. (2020) doi: 10.1016/j.cytogfr.2020.05.002

238. Tay MZ, Poh CM, Rénia L, MacAry PA, Ng LFP. The trinity of COVID19: immunity, inflammation and intervention. Nat Rev Immunol. (2020) 20:363-74. doi: 10.1038/s41577-020-0311-8

239. Zhang W, Zhao Y, Zhang F, Wang Q, Li T, Liu Z, et al. The use of antiinflammatory drugs in the treatment of people with severe coronavirus disease 2019 (COVID-19): the perspectives of clinical immunologists from China. Clin Immunol. (2020) 214:108393. doi: 10.1016/j.clim.2020.108393

240. Bonam SR, Kaveri SV, Sakuntabhai A, Gilardin L, Bayry J. Adjunct immunotherapies for the management of severely Ill COVID-19 patients. Cron Med. (2020) 1:100016. doi: 10.1016/j.xcrm.2020.100016

241. Spinelli FR, Conti F, Gadina M. HiJAKing SARS-CoV-2? The potential role of JAK inhibitors in the management of COVID-19. Sci Immunol. (2020) 5:eabc5367. doi: 10.1126/sciimmunol.abc5367

242. Murthy H, Iqbal M, Chavez JC, Kharfan-Dabaja MA. Cytokine release syndrome: current perspectives. Immunotargets Ther. (2019) 8:43-52. doi: 10.2147/ITT.S202015

243. Le RQ, Li L, Yuan W, Shord SS, Nie L, Habtemariam BA, et al. FDA Approval summary: tocilizumab for treatment of chimeric antigen receptor $\mathrm{T}$ cellinduced severe or life-threatening cytokine release syndrome. Oncologist. (2018) 23:943-7. doi: 10.1634/theoncologist.2018-0028

244. Zhang X, Song K, Tong F, Fei M, Guo H, Lu Z, et al. First case of COVID19 in a patient with multiple myeloma successfully treated with tocilizumab. Blood Adv. (2020) 4:1307-10. doi: 10.1182/bloodadvances.2020001907

245. Cifaldi L, Prencipe G, Caiello I, Bracaglia C, Locatelli F, De Benedetti F, et al. Inhibition of natural killer cell cytotoxicity by interleukin-6: implications for the pathogenesis of macrophage activation syndrome. Arthritis Rheumatol. (2015) 67:3037-46. doi: 10.1002/art.39295

246. Mazzoni A, Salvati L, Maggi L, Capone M, Vanni A, Spinicci M, et al. Impaired immune cell cytotoxicity in severe COVID-19 is IL-6 dependent. J Clin Invest. (2020) 28:138554. doi: 10.1172/JCI138554

247. Cavalli G, De Luca G, Campochiaro C, Della-Torre E, Ripa M, Canetti $\mathrm{D}$, et al. Interleukin-1 blockade with high-dose anakinra in patients with COVID-19, acute respiratory distress syndrome, and hyperinflammation: a retrospective cohort study. Lancet Rheumatol. (2020) 2:E325-31. doi: 10.1016/S2665-9913(20)30127-2

248. Singh YP, Chhabra SC, Lashkari K, Taneja A, Garg A, Chandra A, et al. Hemoadsorption by extracorporeal cytokine adsorption therapy (cytosorb) in the management of septic shock: a retrospective observational study. Int J Artif Organs. (2019) 43:372-8. doi: 10.1177/0391398819891739

249. Bottari G, Merli P, Guzzo I, Stoppa F, Ruggeri A, Di Nardo M, et al. Multimodal therapeutic approach of cytokine release syndrome developing in a child given chimeric antigen receptor-modified $\mathrm{T}$ cell infusion. Crit Care Explor. (2020) 2:e0071. doi: 10.1097/CCE.0000000000000071

250. Tanaka Y, McInnes IB, Taylor PC, Byers NL, Chen L, de Bono S, et al. Characterization and changes of lymphocyte subsets in baricitinibtreated patients with rheumatoid arthritis: an integrated analysis. Arthritis Rheumatol. (2018) 70:1923-32. doi: 10.1002/art.40680 
251. Strehl C, Ehlers L, Gaber T, Buttgereit F. Glucocorticoids-all-rounders tackling the versatile players of the immune system. Front Immunol. (2019) 10:1744. doi: 10.3389/fimmu.2019.01744

252. Favalli EG, Ingegnoli F, De Lucia O, Cincinelli G, Cimaz R, Caporali R. COVID-19 infection and rheumatoid arthritis: faraway, so close! Autoimmun Rev. (2020) 19:102523. doi: 10.1016/j.autrev.2020.102523

253. Oshimi K, Gonda N, Sumiya M, Kano S. Effects of corticosteroids on natural killer cell activity in systemic lupus erythematosus. Clin Exp Immunol. (1980) 40:83-88.

254. Morgan DJ, Davis DM. Distinct effects of dexamethasone on human natural killer cell responses dependent on cytokines. Front Immunol. (2017) 8:432. doi: 10.3389/fimmu.2017.00432

255. Stockman LJ, Bellamy R, Garner P. SARS: systematic review of treatment effects. PLoS Med. (2006) 3:e343. doi: 10.1371/journal.pmed.00 30343

256. Arabi YM, Mandourah Y, Al-Hameed F, Sindi AA, Almekhlafi GA, Hussein MA, et al. Corticosteroid therapy for critically Ill patients with middle east respiratory syndrome. Am J Respir Crit Care Med. (2018) 197:757-67. doi: 10.1164/rccm.201706-1172OC

257. Zhou W, Liu Y, Tian D, Wang C, Wang S, Cheng J, et al. Potential benefits of precise corticosteroids therapy for severe 2019-nCoV pneumonia. Signal Transduct Target Ther. (2020) 5:18. doi: 10.1038/s41392-0200127-9

258. Russell CD, Millar JE, Kenneth Baillie J. Clinical evidence does not support corticosteroid treatment for 2019-nCoV lung injury. Lancet. (2020) 395:4735. doi: 10.1016/s0140-6736(20)30317-2

259. Russell B, Moss C, Rigg A, Van Hemelrijck M. COVID-19 and treatment with NSAIDs and corticosteroids: should we be limiting their use in the clinical setting? Ecancermedicalscience. (2020) 14:1023. doi: 10.3332 /ecancer.2020.1023

260. [No title]. Available online at: https://www.who.int/docs/default-source/ coronaviruse/clinical-management-of-novel-cov.pdf (accessed April 12, 2020).

261. Ni YN, Chen G, Sun J, Liang BM, Liang ZA. The effect of corticosteroids on mortality of patients with influenza pneumonia: a systematic review and meta-analysis. Crit Care. (2019) 23:99. doi: 10.1186/s13054-0192395-8

262. Zha L, Li S, Pan L, Tefsen B, Li Y, French N, et al. Corticosteroid treatment of patients with coronavirus disease 2019 (COVID-19). Med J Aust. (2020) 212:416-20. doi: 10.5694/mja2.50577
263. Amici C, Di Caro A, Ciucci A, Chiappa L, Castilletti C, Martella V, et al. Indomethacin has a potent antiviral activity against SARS coronavirus. Antivir Ther. (2006) 11:1021-30.

264. Lejal N, Tarus B, Bouguyon E, Chenavas S, Bertho N, Delmas B, et al. Structure-based discovery of the novel antiviral properties of naproxen against the nucleoprotein of influenza a virus. Antimicrob Agents Chemother. (2013) 57:2231-42. doi: 10.1128/AAC.02335-12

265. Zheng W, Fan W, Zhang S, Jiao P, Shang Y, Cui L, et al. Naproxen exhibits broad anti-influenza virus activity in mice by impeding viral nucleoprotein nuclear export. Cell Rep. (2019) 27:1875-85.e5. doi: 10.1016/j.celrep.2019.04.053

266. Bancos S, Bernard MP, Topham DJ, Phipps RP. Ibuprofen and other widely used non-steroidal anti-inflammatory drugs inhibit antibody production in human cells. Cell Immunol. (2009) 258:18-28. doi: 10.1016/j.cellimm.2009.03.007

267. Fang L, Karakiulakis G, Roth M. Are patients with hypertension and diabetes mellitus at increased risk for COVID-19 infection? Lancet Respir Med. (2020) 8:e21. doi: 10.1016/S2213-2600(20)30116-8

268. Inaoka $M$, Kimishima $M$, Takahashi $R$, Shiohara $T$. Non-steroidal anti-inflammatory drugs selectively inhibit cytokine production by NK cells and gamma delta T cells. Exp Dermatol. (2006) 15:981-90. doi: 10.1111/j.1600-0625.2006.00505.x

269. Office of the Commissioner. Coronavirus (COVID-19) Update: FDA Continues to Accelerate Development of Novel Therapies for COVID-19. US Food and Drug Administration. (2020) Available online at: https://www. fda.gov/news- events/press-announcements/coronavirus-covid-19-updatefda-continues-accelerate-development-novel-therapies-covid-19 (accessed April 15, 2020).

Conflict of Interest: The authors declare that the research was conducted in the absence of any commercial or financial relationships that could be construed as a potential conflict of interest.

Copyright (c) 2020 Market, Angka, Martel, Bastin, Olanubi, Tennakoon, Boucher, $\mathrm{Ng}$, Ardolino and Auer. This is an open-access article distributed under the terms of the Creative Commons Attribution License (CC BY). The use, distribution or reproduction in other forums is permitted, provided the original author(s) and the copyright owner(s) are credited and that the original publication in this journal is cited, in accordance with accepted academic practice. No use, distribution or reproduction is permitted which does not comply with these terms. 